\title{
Effects of the dose and viability of Saccharomyces cerevisiae. 1. Diversity of ruminal microbes as analyzed by Illumina MiSeq sequencing and quantitative PCR
}

\author{
Y. Jiang, ${ }^{*}$ I. M. Ogunade, ${ }^{*}$ S. Qi,† T. J. Hackmann, ${ }^{*}$ C. R. Staples, ${ }^{*}$ and A. T. Adesogan ${ }^{* 1}$ \\ *Department of Animal Sciences, University of Florida, Gainesville 32611 \\ †DuPont Pioneer, Johnston, IA 50131
}

\begin{abstract}
This study was conducted to examine effects of the dose and viability of supplemental Saccharomyces cerevisiae on the ruminal fermentation and bacteria population and the performance of lactating dairy cows. Four ruminally cannulated lactating cows averaging $284 \pm 18 \mathrm{~d}$ in milk were assigned to 4 treatments arranged in a $4 \times 4$ Latin square design with four 21 -d periods. Cows were fed a total mixed ration containing $41.7 \%$ corn silage, $12.1 \%$ brewer's grains, and $46.2 \%$ concentrate on a dry matter basis. The diet was supplemented with no yeast (control) or with a low dose of live yeast $\left(5.7 \times 10^{7} \mathrm{cfu} / \mathrm{cow}\right.$ per day; LLY $)$, a high dose of live yeast $\left(6.0 \times 10^{8} \mathrm{cfu} / \mathrm{cow}\right.$ per day; HLY), or a high dose of killed yeast $\left(6.0 \times 10^{8} \mathrm{cfu} / \mathrm{cow}\right.$ per day; HDY). Microbial diversity was examined by highthroughput Illumina MiSeq sequencing (Illumina Inc., San Diego, CA) of the V4 region of the $16 \mathrm{~S}$ rRNA gene. The relative abundance of select ruminal bacteria was also quantified by quantitative PCR (qPCR). Adding LLY to the diet increased the relative abundance of some ruminal cellulolytic bacteria (Ruminococcus and Fibrobacter succinogenes) and amylolytic bacteria (Ruminobacter, Bifidobacterium, and Selenomonas ruminantium). Adding live instead of killed yeast increased the relative abundance of Ruminococcus and F. succinogenes; adding HDY increased the relative abundance of Ruminobacter, Bifidobacterium, Streptococcus bovis, and Selenomonas ruminantium. The most dominant ( $\geq 1 \%$ of total sequences) bacteria that responded to LLY addition whose functions are among the least understood in relation to the mode of action of yeast include Paraprevotellaceae, CF231, Treponema, and Lachnospiraceae. Future studies should aim to speci-
\end{abstract}

Received April 3, 2016.

Accepted August 30, 2016.

${ }^{1}$ Corresponding author: adesogan@ufl.edu ate, culture, and examine the function of these bacteria to better understand their roles in the mode of action of yeast. A relatively precise relationship was detected between the relative abundance of $F$. succinogenes $\left(\mathrm{R}^{2}\right.$ $=0.67$ ) from qPCR and MiSeq sequencing, but weak relationships were detected for Megasphaera elsdenii, Ruminococcus flavefaciens, and S. ruminantium $\left(\mathrm{R}^{2} \leq\right.$ $0.19)$.

Key words: Saccharomyces cerevisiae, dairy cows, rumen bacteria, MiSeq sequencing

\section{INTRODUCTION}

Yeasts are microbial feed additives that have been widely used for decades in the dairy industry (Beauchemin et al., 2008). Several studies have examined the effects of yeasts on ruminal fermentation (ChaucheyrasDurand and Fonty, 2001; Lila et al., 2004; Krause and Oetzel, 2006) and the performance of ruminant livestock (Erasmus et al., 2005; Bach et al., 2007; Ferraretto et al., 2012). Some studies have examined the effects of yeast on the abundance of ruminal protozoa (ChaucheyrasDurand and Fonty, 2002), lactate-utilizing bacteria (Chaucheyras et al., 1996; Rossi et al., 2004), and cellulolytic bacteria (Callaway and Martin, 1997). Such studies are important because the beneficial effects of yeast on milk yield and weight gain are attributed largely to their effects on ruminal bacteria (Pinloche et al., 2013). However, most of these studies have focused only on a few specific bacteria due to the limitations of the traditional culture or quantitative PCR (qPCR) techniques used. Several studies have used sequencing of the $16 \mathrm{~S}$ rRNA gene to provide a more complete understanding of ruminal bacterial diversity (Whitford et al., 1998; Tajima et al., 1999; Kocherginskaya et al., 2001). Relative to traditional methods, next-generation high-throughput sequencing is a newer method that provides a more complete relative quantification of microbial community composition, and it may allow a more precise inference of their functions (Zhang et al., 
2011) in a much shorter time and at considerably less expense. Very few studies have examined the effects of yeasts on the ruminal microbial community using next-generation high-throughput sequencing systems. Pinloche et al. (2013) used 454 pyrosequencing to demonstrate that addition of live yeast increased the populations of main fibrolytic and lactate-utilizing bacteria in the rumen. Based on 454 pyrosequencing, Sandri et al. (2014) reported that lyophilized live yeast supplementation increased the abundance of Bacillus and dry brewer's yeast supplementation increased the abundance of an unassigned genus of family Erysipelotrichaceae. However, they examined only the effects on the liquid ruminal fraction.

The Illumina MiSeq sequencing system (Illumina Inc., San Diego, CA) has higher throughput per run, lower error rates, and greater depth and breadth of coverage than the 454 pyrosequencing system (Loman et al., 2012; Frey et al., 2014). Therefore, the MiSeq sequencing system may provide a more detailed characterization of the effects of yeast on ruminal diversity. This is particularly important because the beneficial effects of yeast on milk yield and weight gain have been attributed to only a few of the diverse microorganisms in the rumen. Moreover, little is known about the effects of the dose and viability of live yeast on the ruminal microbiome. Such information is needed to understand the relative effects and modes of action of live yeast and yeast culture to increase their efficacy.

The objective of this study was to examine the effect of the dose and viability of live yeast on the diversity of the ruminal microbial population using highthroughput MiSeq 16S rDNA sequencing and qPCR techniques. A second objective was to examine the relationship between estimates of the relative abundance of certain ruminal bacteria from both methods. Because all yeast treatments increased or tended to increase NDF and ADF digestibility (Jiang et al., 2016) and only the low dose of live yeast increased milk production, we hypothesized that all yeast treatments would increase the relative abundance of cellulolytic ruminal bacteria, but the response would be greatest for the low dose of live yeast. We also hypothesized that similar bacterial diversity responses to yeast treatments would be achieved with qPCR and MiSeq sequencing, and that MiSeq sequencing would reveal several uncultured or unknown ruminal bacteria that are important candidates for future studies because of their response to yeast supplementation.

\section{MATERIALS AND METHODS}

All experimental cows were managed according to the guidelines approved by the University of Florida
Institute of Food and Agricultural Sciences Animal Research Committee.

\section{Animals, Housing, and Feeding}

The experiment was conducted from December 2013 to April 2014. Four ruminally cannulated lactating primiparous Holstein cows at $284 \pm 18$ DIM were randomly assigned to 1 of 4 treatment sequences in a 4 $\times 4$ Latin square experimental design with four 21-d experimental periods.

Cows were housed in a freestall, open-sided barn with sand-bedded stalls $(1.14 \times 2.31 \times 1.22 \mathrm{~m})$. The experimental pens were fitted with 2 rows of fans (1 fan/6 linear meters) with low-pressure nozzles for cooling the cows; the nozzles were activated by ambient temperatures of $21.1^{\circ} \mathrm{C}$. Artificial light was provided by suspended fluorescent bulbs. Water was freely available at all times. Areas between the feed bunks and the freestalls were flushed twice daily to remove manure.

Each cow was randomly assigned to a feeding gate (Calan Broadbent feeding system; American Calan Inc., Northwood, NH) for measurement of individual cow feed intake. All cows were trained to eat from their specific Calan gate during a 5 -d period before a $10-\mathrm{d}$ pre-study covariate period, when cows were fed the control diet and DMI and milk production were measured.

\section{Diets and Treatments}

Cows received a typical mid-lactation TMR formulated to meet or exceed the nutrient requirements of dairy cows producing at least $30 \mathrm{~kg}$ of milk (NRC, 2001) using CPM-Dairy software (version 3.0.10; www. cpmdairy.net). Diets consisted of corn silage, a concentrate mixture, and a vitamin and mineral premix. All cows were offered $110 \%$ of their feed intake on the previous day.

Cows were randomly assigned to the following treatments: (1) A control treatment fed no yeast; (2) a low dose of live yeast (LLY; $5.7 \times 10^{7} \mathrm{cfu} / \mathrm{cow}$ per day); (3) a high dose of live yeast (HLY; $6.0 \times 10^{8} \mathrm{cfu} /$ cow per day); and (4) a high dose of killed yeast (HDY; fed 6.0 $\times 10^{8} \mathrm{cfu} / \mathrm{cow}$ per day). Yeast in the HDY treatment were killed in the liquid form by heating in a water bath for $1.5 \mathrm{~h}$ at $80^{\circ} \mathrm{C}$. Exactly $5 \mathrm{~g}$ of a maltodextrin carrier containing the respective yeast treatment was top-dressed on the relevant TMR at each of the 2 daily feedings. Allotments of yeast for each daily feeding were prepared $4 \mathrm{~d}$ before the beginning of each period and freeze-dried. The specific yeast used was a proprietary strain of Saccharomyces cerevisiae (Dupont Pioneer, Johnston, IA) that was isolated from corn silage. 


\section{Rumen Sampling}

Ruminal fluid was collected at $0 \mathrm{~h}$ (immediately before feeding) on $\mathrm{d}-1$ of period 1 (covariate) and at 0 , $2,4,6,8$, and $10 \mathrm{~h}$ after the morning feeding on $\mathrm{d} 21$ of each period. Samples were filtered through 4 layers of cheesecloth to separate solid and liquid fractions, which were both frozen $\left(-80^{\circ} \mathrm{C}\right)$ and dispatched on dry ice to the Dupont Pioneer Analytical-Genomics Technologies laboratory (Johnston, IA) for further analysis.

\section{DNA Extraction and Preparation}

Each ruminal liquid or solid sample $(\sim 25 \mathrm{~g})$ was ground coarsely in liquid nitrogen in a precooled $\left(-196^{\circ} \mathrm{C}\right)$ mortar, transferred to a precooled $\left(-196^{\circ} \mathrm{C}\right)$ grinding vial equipped with a stainless steel impactor and then ground in liquid nitrogen at 6 cycles per second for 6 min and then at 8 cycles per second for 6 min in an enclosed freezer mill (no. 6970EFM; SPEX SamplePrep, Metuchen, NJ). The DNA was then extracted and purified from $0.20 \mathrm{~g}$ of ground samples with a PowerSoil DNA Isolation Kit (MOBIO Laboratories Inc., Carlsbad, CA). The integrity of the DNA was verified by agarose $(0.7 \%)$ gel electrophoresis, and the DNA was stored at $-20^{\circ} \mathrm{C}$ until further use.

\section{IIlumina MiSeq Sequencing (Experiment 1)}

The V4 region of the $16 \mathrm{~S}$ rRNA gene was PCR-amplified with primers 515F (5'-GTGCCAGCMGCCGCGGTAA-3') and 806R (5'-GGACTACHVGGGTWTCTAAT-3') (Caporaso et al., 2010) using Accuprime Pfx DNA polymerase (Life Technologies, Carlsbad, CA) with a reaction volume of $20 \mu \mathrm{L}$. A 12-bp barcode for sample identification was included in the forward primers. Amplification was achieved with the Applied Biosystems Veriti Thermocycler (Life Technologies) using the following steps: (1) initial denaturation at $95^{\circ} \mathrm{C}$ for $2 \mathrm{~min}$; (2) 30 cycles of further denaturation at $95^{\circ} \mathrm{C}$ for $15 \mathrm{~s}$, annealing at $50^{\circ} \mathrm{C}$ for $30 \mathrm{~s}$, and extension at $68^{\circ} \mathrm{C}$ for $1 \mathrm{~min}$; (3) concluding extension at $68^{\circ} \mathrm{C}$ for $7 \mathrm{~min}$. All PCR reactions were performed in triplicate, and PCR products were combined, assessed for integrity by agarose $(2 \%)$ gel electrophoresis, quantified using the Qubit dsDNA BR Assay Kit in accordance with the manufacturer's instructions (Life Technologies; https://tools.thermofisher.com/content/sfs/manuals/ Qubit_dsDNA_BR_Assay_UG.pdf) and subsequently pooled in equal proportions based on DNA concentration. Pooled amplicons were then purified using a QIAquick Gel Extraction Kit (Qiagen; Venlo, Limburg, Belgium). Paired-end reads with $250 \mathrm{bp}$ were generated using the MiSeq v. Four sequencing platform (Illumina
Inc., San Diego, CA) from the purified amplicons. Sequences were trimmed, quality-filtered, and de-convoluted based on the 12-bp barcode sequence using an in-house Dupont Pioneer pipeline. All paired ends were joined, and sequences with short reads were extended by merging paired-end reads using FLASH (Magoč and Salzberg, 2011). Any read pairs that could not be assembled and any single reads were discarded.

\section{Sequence Analysis}

Sequences were trimmed, quality-filtered (with a minimum per base $\mathrm{Q}$ score of 16 and a minimum average Q score of 20) and de-convoluted based on the 12bp barcode sequence using an in-house Dupont Pioneer pipeline. Sequences were processed and analyzed using Quantitative Insights Into Microbial Ecology (QIIME; v. 1.8.0) according to Caporaso et al. (2010). Chimeras were removed by script identify_chimeric_seqs.py with the usearch61 option (Edgar, 2010). The Screen.seqs function in Mothur (Schloss et al., 2009) was used to remove sequences that were longer than $275 \mathrm{bp}$, with ambiguous bases, or with homopolymers longer than 8 bases. Operational taxonomic units (OTU) were picked at a $97 \%$ identity threshold using the pick_de_novo_ otus.py script. Representative OTU were classified by Uclust (Edgar, 2010) against the Greengenes reference database (release 12_10; DeSantis et al., 2006). Singletons were removed with the filter_otus_from_otu_table. py script (Bokulich et al., 2013) before further analysis. The number of reads were normalized to 13,787 and within $(\alpha)$ - and between $(\beta)$-sample phylogenetic diversity and the relative abundance of OTU were compared with the core_diversity_analyses.py script as described by Lozupone and Knight (2005). Unweighted UniFrac distances (Lozupone and Knight, 2005) between sets of taxa in the phylogenetic tree were used to build principal coordinate analysis (PCoA) plots.

\section{Quantitative PCR Analysis (Experiment 2)}

Primer sets used for qPCR analysis of select rumen bacteria and protozoa are listed in Table 1. Fibrobacter succinogenes, Ruminococcus albus, Ruminococcus flavefaciens, Selenomonas ruminantium, Streptococcus bovis, Butyrivibrio fibrisolvens, Megasphaera elsdenii, and Prevotella ruminicola primer sets were based on those from Stevenson and Weimer (2007). A total bacteria primer set (Maeda et al., 2003) that amplifies all bacteria was selected as a reference primer set for the bacteria-specific primer sets. The population of the Saccharomyces cerevisiae strain used in this study was quantified by qPCR using primers TM4F and TM4R; Research Disclosure database number 612005). The 
protozoa population was quantified by qPCR using the primers $316 \mathrm{~F}$ and 539R and methods described by Sylvester et al. (2004), except that the platinum Taq DNA polymerase was replaced with a QuantiTect Multiplex PCR Master Mix (Quiagen).

Quantification of the selected ruminal microorganisms was performed with the Applied Biosystems ViiA7 platform (Life Technologies) using fluorescence detection of EVAgreen dye (Biotium, Hayward, CA). Each microtiter plate well contained the following: $4.75 \mu \mathrm{L}$ of $2 \times$ QuantiTect Multiplex PCR Mastermix (Qiagen), which contained DNA polymerase, reaction buffer, deoxynucleotide triphosphates (dNTP), and ROX dye (Life Technologies) as a passive reference; forward and reverse primers at a final concentration of $360 \mathrm{n} M ; 0.25$ $\mu \mathrm{L}$ of EVAgreen; $0.1 \mu \mathrm{L}$ of uracil N-glycosylase, $1.0 \mu \mathrm{L}$ of each sample; and $3.83 \mu \mathrm{L}$ of distilled water to give a total of approximately $10 \mu \mathrm{L}$ per well. The plate was briefly centrifuged and placed in the thermocycler for analysis. Amplification consisted of an initial hold of $95^{\circ} \mathrm{C}$ for $15 \mathrm{~min}$, followed by 40 cycles of $94^{\circ} \mathrm{C}$ for $60 \mathrm{~s}$ and $60^{\circ} \mathrm{C}$ for $60 \mathrm{~s}$.

For bacteria standards, $16 \mathrm{~S}$ rRNA genes of the species of interest were retrieved from GenBank and the portion of DNA fragments that contained the primer binding sites were synthesized at Integrated DNA Technologies Inc. (Coralville, IA). The strains of the individual species used were B. fibrisolvens strain H17c, $F$. succinogenes strain S85, M. elsdenii strain T81, $P$. ruminicola $23, R$. albus strain $7, R$. flavefaciens strain FD1, S. ruminantium ssp. lactilytica TAM6421, and Strep. bovis strain JB1. The protozoa standard was generated by PCR using P.SSU-54f/P.SSU-1747r primers (Sylvester et al., 2004) with pooled rumen DNA samples as the template. Copy numbers of protozoa 18S rRNA gene were calculated based on the molecular weight as reported by Sylvester et al. $\left(2004 ; 9.4 \times 10^{5}\right.$ $\mathrm{g} / \mathrm{mol}$ or $6.4 \times 10^{8}$ copies $/ \mathrm{ng}$ of PCR product). The number of bacterial and protozoal DNA molecules synthesized were calculated, serially diluted $\left[10^{7}, 10^{6}, 10^{5}\right.$, $10^{4}, 10^{3}, 10^{2}, 1$ molecule(s) per PCR reaction], and used as the standards for quantifying the species of interest by qPCR.

Gene copy numbers (for bacteria) of each sample were calculated based on cycle threshold values from standard curves. The relative abundance of protozoa and specific bacteria was calculated by dividing the population of protozoa and the bacteria of interest by that of the total bacteria reference.

\section{Statistical Analysis}

The experimental design was a single $4 \times 4$ Latin square with 4 experimental units per treatment. The within-sample phylogenetic distance metric was compared at the highest rarefaction depth using the GLM procedure of SAS version 9.3 (SAS Institute Inc., Cary, NC). A nonparametric Monte Carlo test with no Bonferroni correction was used to compare the withintreatment and between-treatment UniFrac distances.

The relative abundance of OTU was analyzed using the GLIMMIX procedure of SAS. The model for analyzing the data is expressed in the form:

$$
\begin{aligned}
\mathrm{Y}=\mu & +\mathrm{T}_{\mathrm{i}}+\mathrm{P}_{\mathrm{j}}+\mathrm{C}_{\mathrm{k}}+\mathrm{CV}_{\mathrm{l}}+\mathrm{TH}_{\mathrm{m}} \\
& +(\mathrm{T} \times \mathrm{TH})_{\mathrm{im}}+\varepsilon_{\mathrm{ijklm}},
\end{aligned}
$$

where $\mathrm{Y}$ is the dependent variable, $\mu$ is the overall mean, $T_{i}$ is the treatment effect, $P_{j}$ is the period effect, $\mathrm{C}_{\mathrm{k}}$ is the cow effect (random), $\mathrm{CV}_{1}$ is the covariate effect, $\mathrm{TH}_{\mathrm{m}}$ is the effect of sampling time, $(\mathrm{T} \times \mathrm{TH})_{\mathrm{im}}$ is the interaction between treatment and time, and $\varepsilon_{\mathrm{ijkkm}}$ is the residual error.

Normality was tested by examining the distribution of residuals. Denominator degrees of freedom were estimated using the Kenward-Roger option in the MODEL statement. Time was used in the repeated-measures statement with autoregressive order 1 repeated measure covariance structure, which was chosen because it gave the smallest Akaike information criterion values, and because measurements taken close together were more correlated than those that were farther apart (SAS Institute, 2016). Preplanned nonorthogonal contrasts that were examined to compare means included the following: control vs. LLY (effect of supplementation with LLY), LLY versus HLY (effect of the dose of live yeast), average of LLY and HLY versus HDY (effect of supplementing with live vs. killed yeast), and control versus HDY (effect of supplementing with killed yeast). Treatment effects and their interactions were declared significant at $P \leq 0.05$, and tendencies to significance were declared at $0.05 \leq P \leq 0.15$. To compare the quantification of key ruminal bacteria by qPCR and MiSeq sequencing, the relationship between the relative percentage of $F$. succinogenes, $R$. flavefaciens, and $S$. ruminantium measured by both methods was examined using the REGRESSION procedure of SAS.

\section{RESULTS}

\section{Sequencing Depth and Coverage and Relative Abundance of Taxa}

The quality-filtered reads for $16 \mathrm{~S}$ rRNA sequences were demultiplexed and assembled, yielding 13,374,890 sequences in total with a median sequence length of 253 bases and an average coverage of 55,728 sequences per 
YEAST AND RUMEN BACTERIA

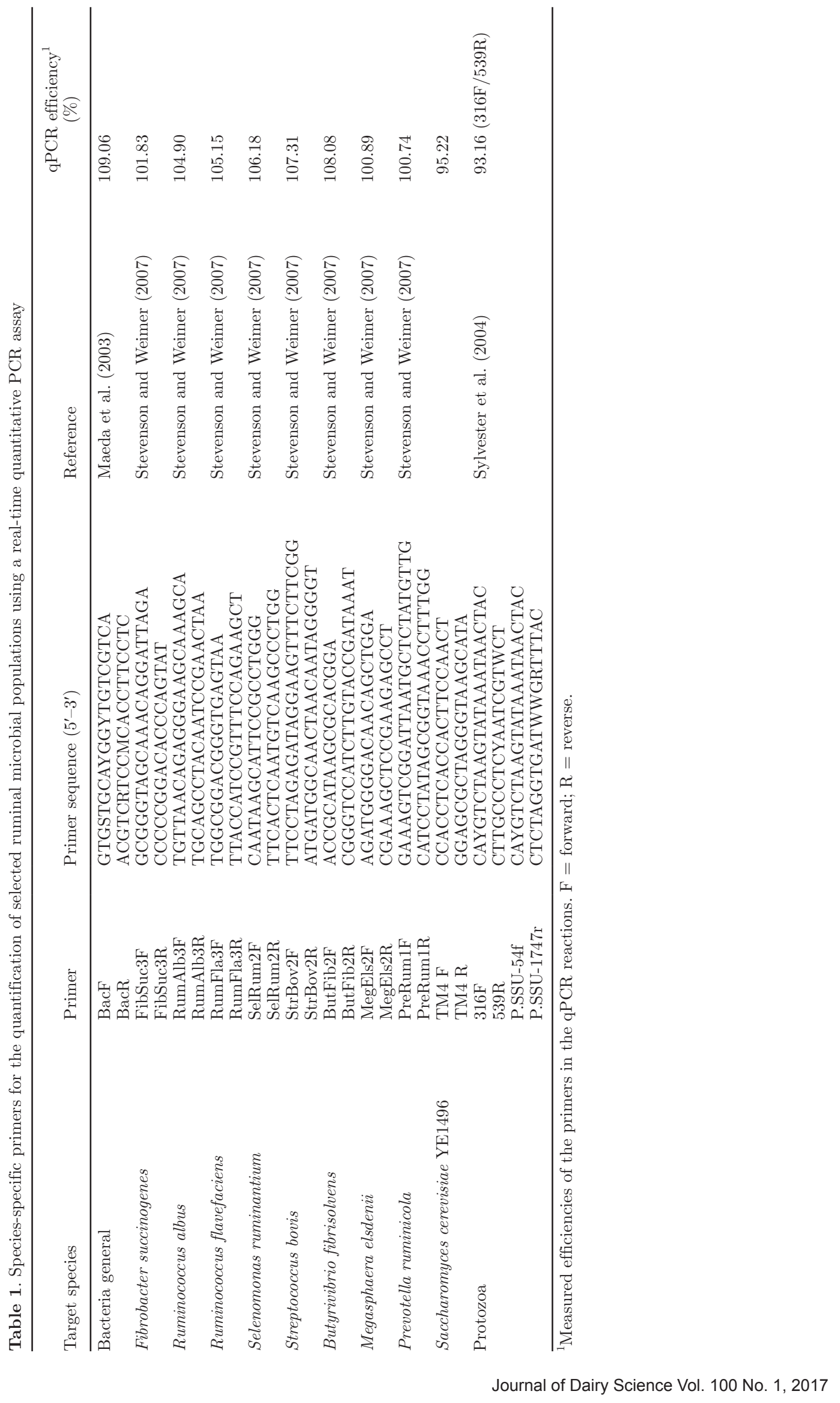


sample. The overall number of OTU detected by the analysis was 75,355 , based on $97 \%$ nucleotide sequence identity between reads.

The diversity of bacteria in the solid and liquid fraction differed (Figures 1 and 2). Prevotella dominated (24\%) the solid fraction of the ruminal contents, followed by Fibrobacter (10\%), and then Treponema (6\%; Figure 1). In the liquid fraction, Prevotella accounted for $50 \%$ of ruminal bacteria, followed by Succiniovibrionaceae $(7 \%)$, and then by several bacteria that each had a relative abundance of approximately $2 \%$, including Butyrivibrio, Lachnospiraceae, Ruminococcus, and Treponema (Figure 2). Because OTU were not classified to the species level, we further compared representative sequences from OTU from the Prevotella genus against the $16 \mathrm{~S}$ sequences from $P$. ruminicola strain 23 and $P$. bryantii B14 using BLAST to suggest what percentage of the Prevotella, the most abundant genus, corresponded to well-known species such as P. ruminicola or $P$. bryantii. Sequences that had expectation values less than $1 \times 10^{-100}$ and over $99 \%$ identity to reference sequences were classified as the respective species. Based on these classifications, P. bryantii accounted for 0.83 and $0.72 \%$ of Prevotella in the solid and liquid fraction, respectively, whereas $P$. ruminicola accounted for $13.11 \%$ and $16.56 \%$ of Prevotella in the solid and liquid fraction, respectively. However, these results should be carefully interpreted, because the analysis was based solely on the V4 region of $16 \mathrm{~S}$ and may or may not reflect the classification by the full-length $16 \mathrm{~S}$ gene.

\section{Within-Sample ( $\alpha$ ) and Between-Sample ( $\beta$ ) Diversity}

The average Good's coverage of all the samples was $0.91 \pm$ SEM 0.001 (Supplemental Material; https:// doi.org/10.3168/jds.2016-11263), indicating that the sequencing depth was adequate for reliable analysis of the microbial community of all the samples. Treatments did not affect within-sample $(\alpha)$ phylogenetic diversity (Chao1 estimates; Figure 3), and this was confirmed statistically $(P>0.15)$. The PCoA plots of between-sample $(\beta)$ phylogenetic diversity (Figure 4) show that bacteria in the liquid and solid samples clustered separately, and this was also confirmed by

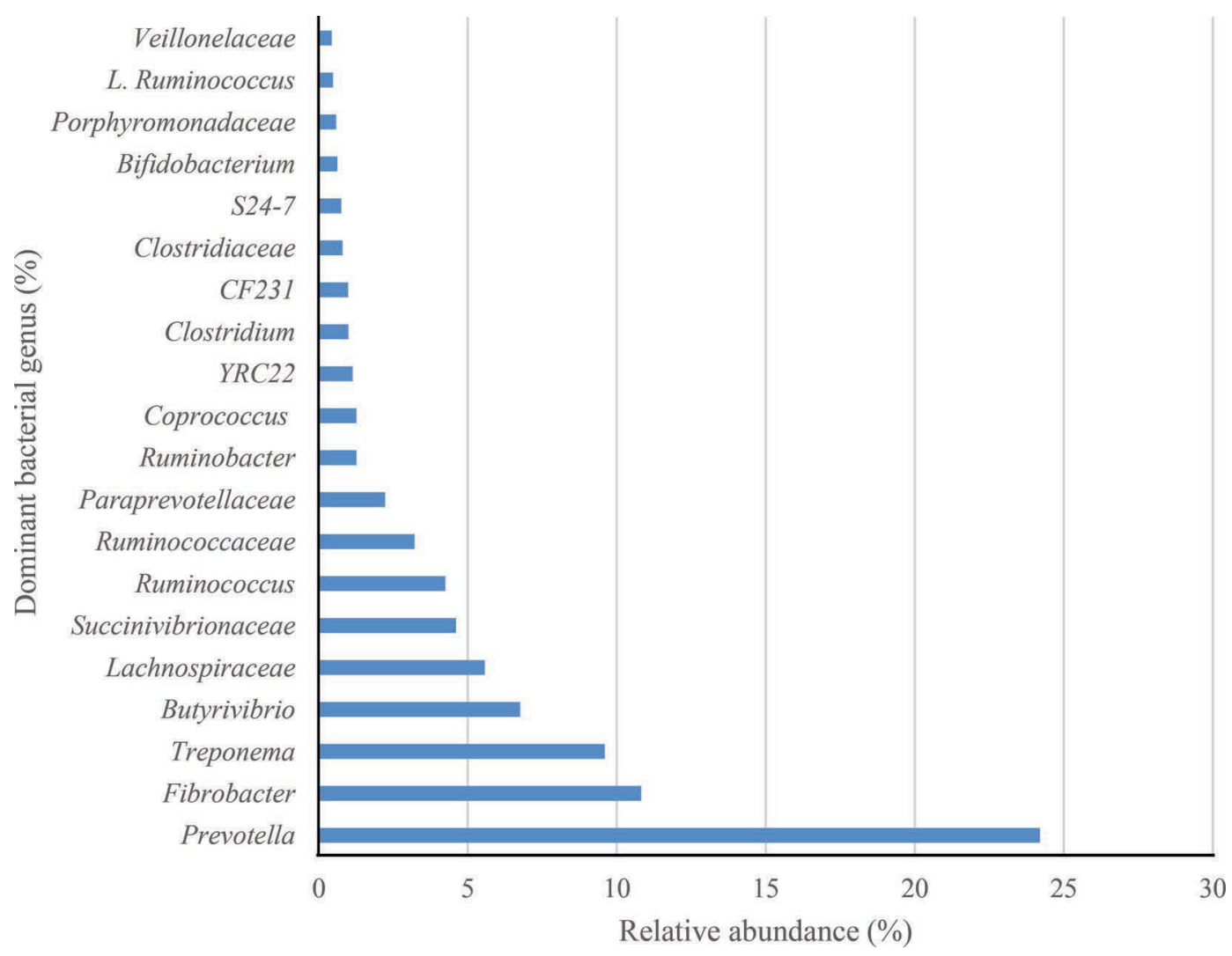

Figure 1. Relative abundance (\%) of the 20 most dominant bacteria genera or families in the ruminal solid fraction of dairy cows as analyzed by MiSeq (Illumina Inc., San Diego, CA) 16S rDNA sequencing (experiment 1). L. Ruminococcus = Lachnospiraceae Ruminococcus; Veillonelaceae, Porphyromonadaceae, Clostridiaceae, Paraprevotellaceae, Ruminococcaceae, Succinivibrionaceae, and Lachnospiraceae represent unknown genera in the respective families. Color version available online. 


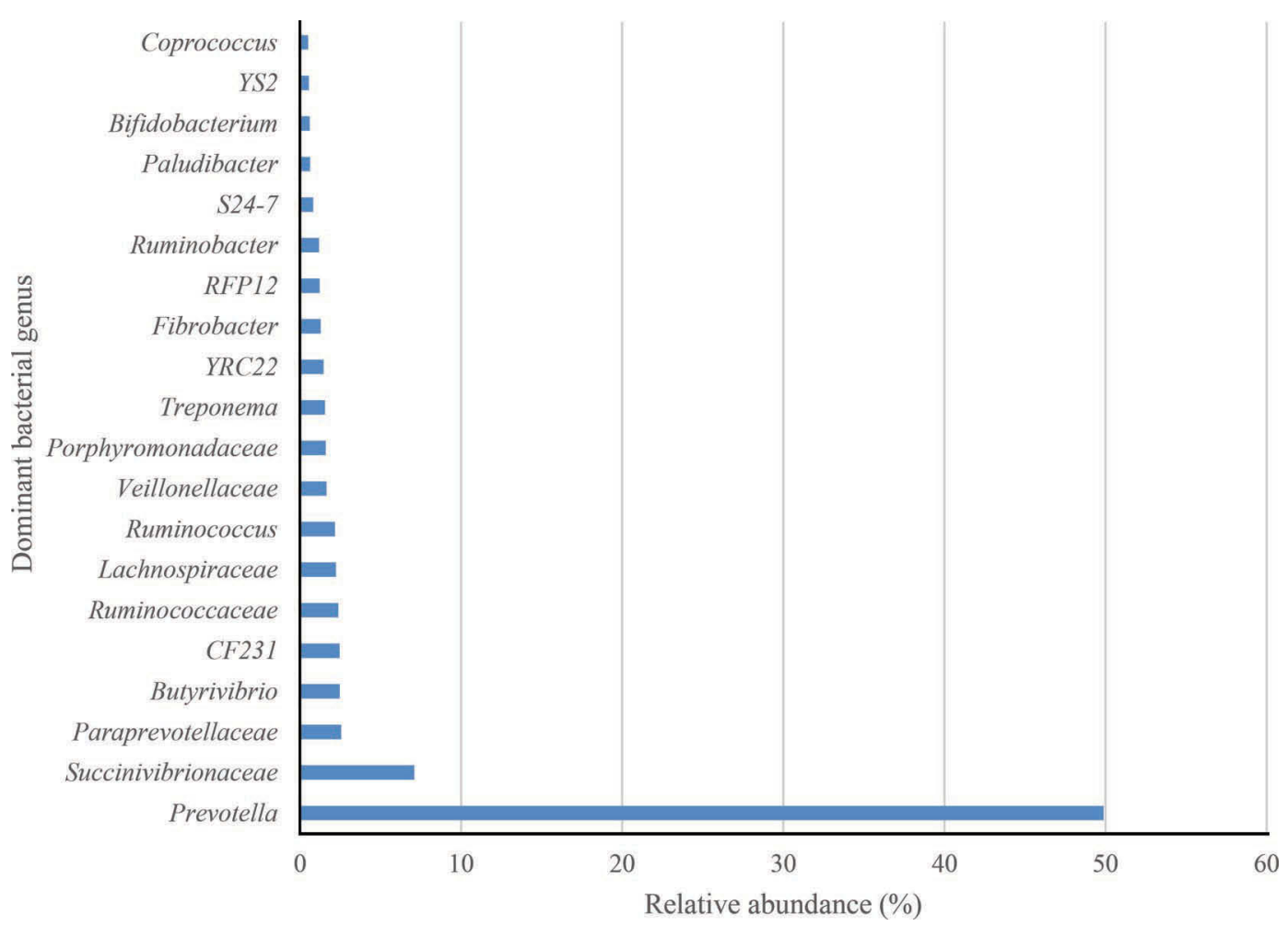

Figure 2. Relative abundance (\%) of the 20 most dominant bacteria genera or families in the ruminal liquid fraction of dairy cows as analyzed by MiSeq (Illumina Inc., San Diego, CA) 16S rDNA sequencing (experiment 1). YS2 = uncultured or unidentified taxa; Porphyromonadaceae, Veillonelaceae, Lachnospiraceae, Ruminococcaceae, Paraprevotellaceae, and Succinivibrionaceae represent unknown genera in the respective families. Color version available online.

statistical analysis $(P=0.001)$. These findings indicate that compositional differences existed among the bacterial communities of the liquid and solid fractions, which has been observed by Tajima et al. (1999) and Michalet-Doreau et al. (2001). The Monte Carlo test revealed that the within-treatment variation in the unweighted UniFrac distances used to estimate $\beta$ diversity was smaller $(P=0.001)$ than the between-treatment variation (Figure 4$)$. This suggests that treatments had different effects on ruminal diversity. The time of taking ruminal samples did not affect $\beta$ diversity (Figure $5 ; P>0.15)$.

\section{Treatment Effects on Dominant Bacteria Groups Analyzed by MiSeq Sequencing}

Solid Fraction. Although $65.8 \%$ of sequences could be assigned to the genus level using GreenGene as the reference, only $7.8 \%$ of the sequences could be assigned to the species level; 87.8, 98.4, 98.5, and $98.7 \%$ of the sequences could be assigned to family, order, class, and phylum, respectively.

The relative percentage in the solid fraction of Prevotella, Succinivibrionaceae, and Fibrobacter, which were among the most dominant bacteria, were unaf- fected by treatment $(P>0.15$, Table 2$)$, but it is unclear if changes in the relative abundance of the species occurred. Adding LLY to the diet decreased the relative abundance of Treponema $(P=0.01)$, Lachnospiraceae $(P=0.07)$, and Coprococcus $(P=0.04)$, but increased that of CF231 (an uncultured/unidentified taxon in family Paraprevotellaceae; $P=0.06)$, Ruminobacter $(P$ $=0.10)$, Porphyromonadaceae $(P=0.13)$, and Bifidobacterium $(P=0.01)$. Increasing the live yeast dose (HLY vs. LLY) increased the relative abundance of Treponema $(P=0.03)$ but decreased that of Paraprevotellaceae $(P=0.11)$, CF231 $(P=0.11)$, and Bifidobacterium $(P=0.12)$. Adding live yeast instead of killed yeast to the diet increased the relative abundance of Ruminococcus $(P=0.07)$ and decreased that of S24-7 (uncultured/unidentified taxon in order Bacteroidales; $P=0.01)$ and Clostridiaceae $(P=0.04)$. Adding HDY decreased the relative abundance of Lachnospiraceae $(P$ $=0.06)$ and Coprococcus $(P=0.01)$ and increased that of Ruminobacter $(P=0.02)$, Porphyromonadaceae $(P=$ $0.12)$, and Bifidobacterium $(P=0.03)$.

Liquid Fraction. Table 3 shows treatment effects on dominant bacteria in the ruminal liquid fraction. Adding LLY to the diet increased the relative abundance of Butyrivibrio $(P=0.11)$, Ruminococcus $(P=$ 


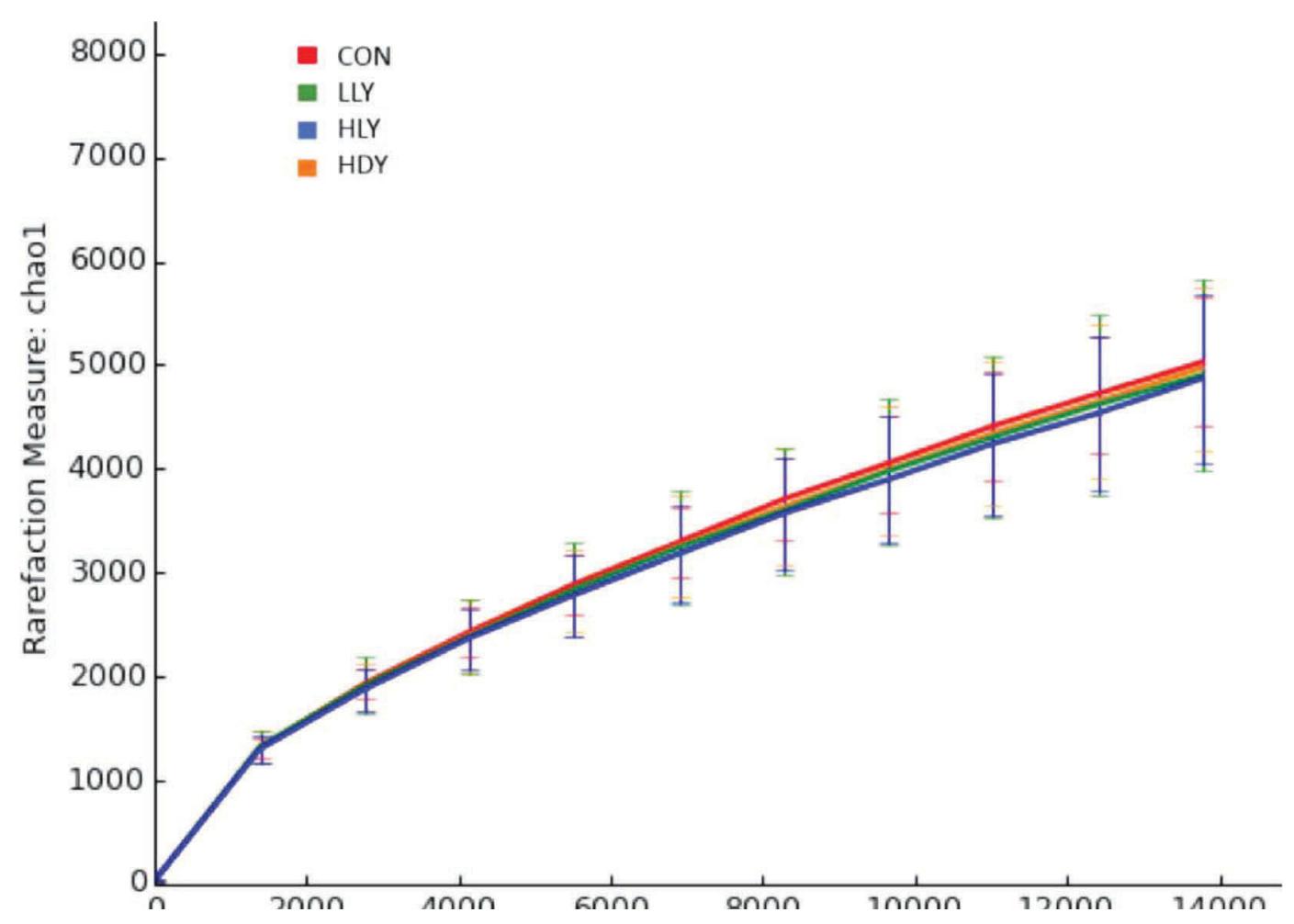

Figure 3. Phylogenetic diversity for bacterial communities in ruminal fluid of cows fed diets supplemented without or with 2 doses of live yeast or 1 dose of killed yeast (experiment 1$)$. Values are mean \pm SEM. CON (control) $=$ no yeast treatment; LLY and HLY $=$ low $\left(5.7 \times 10^{7}\right.$ $\mathrm{cfu} /$ cow per day) and high $\left(6.0 \times 10^{8} \mathrm{cfu} / \mathrm{cow}\right.$ per day) doses of live Saccharomyces cerevisiae YE1496 (DuPont Pioneer, Johnston, IA); HDY $=$ high dose $\left(6.0 \times 10^{8} \mathrm{cfu} / \mathrm{cow}\right.$ per day $)$ of killed Saccharomyces cerevisiae YE1496. The phylogenetic diversity metric was compared across treatments at highest rarefaction depth. No treatment effects were evident $(P>0.15)$. Color version available online.

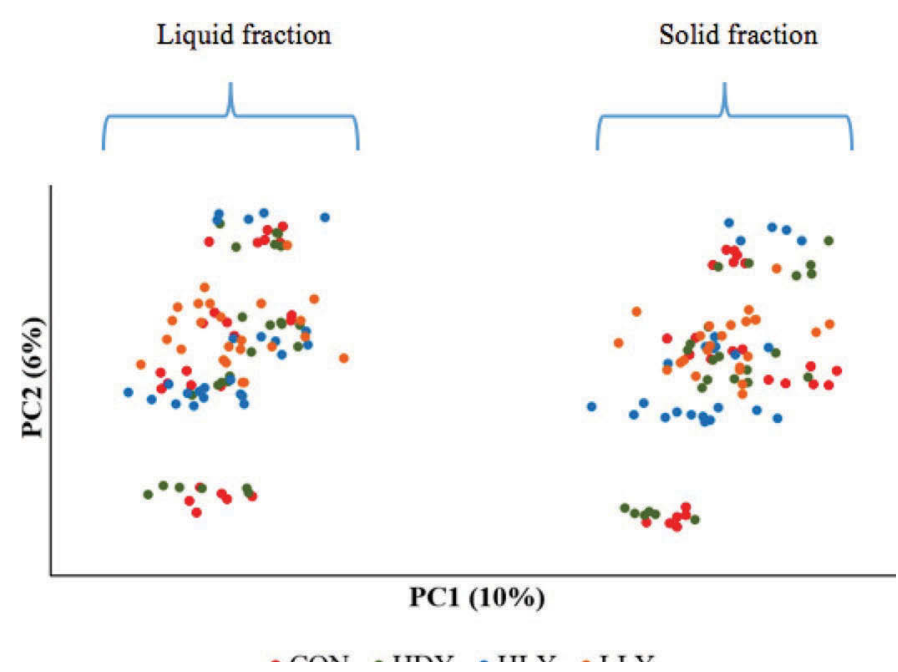

Figure 4. Principal coordinate (PC) analysis plot of $\beta$ diversity of rumen samples from cows fed diets supplemented without or with 2 doses of live yeast or 1 dose of killed yeast (experiment 1). CON $($ control $)=$ no yeast treatment: LLY and HLY $=$ low $\left(5.7 \times 10^{7} \mathrm{cfu} /\right.$ cow per day) and high $\left(6.0 \times 10^{8} \mathrm{cfu} / \mathrm{cow}\right.$ per day $)$ doses of live Saccharomyces cerevisiae YE1496 (DuPont Pioneer, Johnston, IA); $\mathrm{HDY}=$ high dose $\left(6.0 \times 10^{8} \mathrm{cfu} / \mathrm{cow}\right.$ per day $)$ of killed Saccharomyces cerevisiae YE1496. Color version available online.
$0.06)$, and Bifidobacterium $(P=0.02)$ and decreased that of Treponema ( $P=0.14)$, RFP12 (uncultured/ unidentified taxon in order WCHB1-41; $P=0.03$ ), and Paludibacter $(P=0.02)$. Increasing the live yeast dose tended to decrease the relative abundance of Bifidobac-

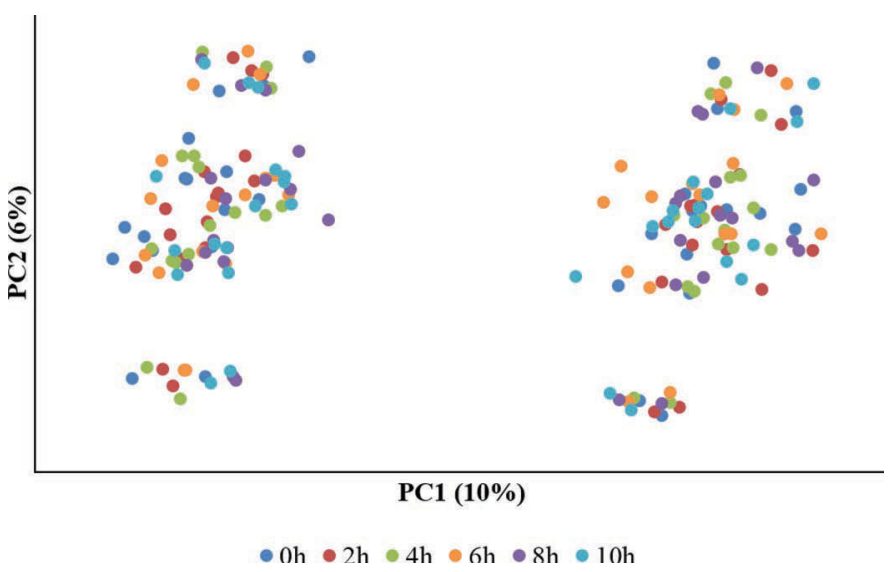

Figure 5. Principal coordinate (PC) analysis plot of $\beta$ diversity of rumen samples taken at different times after the morning feeding of dairy cows fed different doses of live yeast and 1 dose of killed yeast (experiment 1). Color version available online. 
Table 2. Effect of supplementing 2 levels of live yeast or 1 level of killed yeast on the bacterial composition (relative \%) of the ruminal solid fraction of dairy cows as analyzed by MiSeq (Illumina Inc., San Diego, CA) sequencing (experiment 1)

\begin{tabular}{|c|c|c|c|c|c|c|c|c|c|}
\hline \multirow[b]{2}{*}{ Genus } & \multicolumn{4}{|c|}{ Treatment $^{1}$} & \multirow[b]{2}{*}{ SEM } & \multicolumn{4}{|c|}{ Contrast $P$-value } \\
\hline & Control & LLY & HLY & HDY & & $\begin{array}{l}\text { Control vs. } \\
\text { LLY }\end{array}$ & $\begin{array}{c}\text { LLY } \\
\text { vs. HLY }\end{array}$ & $\begin{array}{c}\text { LLY + HLY } \\
\text { vs. HDY }\end{array}$ & $\begin{array}{c}\text { Control vs. } \\
\text { HDY }\end{array}$ \\
\hline Prevotella & 23.4 & 25.1 & 23.8 & 24.5 & 1.03 & 0.26 & 0.38 & 0.96 & 0.45 \\
\hline Succinivibrionaceae $^{2}$ & 4.51 & 4.61 & 4.26 & 5.04 & 0.77 & 0.91 & 0.71 & 0.43 & 0.57 \\
\hline Fibrobacter & 10.7 & 10.2 & 12.4 & 9.98 & 1.18 & 0.75 & 0.17 & 0.34 & 0.66 \\
\hline Treponema & 11.1 & 7.51 & 10.4 & 9.40 & 1.09 & 0.01 & 0.03 & 0.67 & 0.17 \\
\hline Ruminococcus & 4.30 & 4.26 & 4.63 & 3.80 & 0.30 & 0.92 & 0.33 & 0.07 & 0.20 \\
\hline Ruminococcaceae $e^{2}$ & 3.24 & 3.20 & 3.31 & 3.11 & 0.12 & 0.82 & 0.51 & 0.33 & 0.45 \\
\hline Paraprevotellaceae $^{2}$ & 2.18 & 2.44 & 2.03 & 2.25 & 0.22 & 0.28 & 0.11 & 0.92 & 0.74 \\
\hline CF231 & 0.87 & 1.13 & 0.91 & 1.06 & 0.11 & 0.06 & 0.11 & 0.73 & 0.16 \\
\hline YRC22 & 1.21 & 1.20 & 1.05 & 1.09 & 0.09 & 0.91 & 0.21 & 0.74 & 0.31 \\
\hline Veillonellaceae $^{2}$ & 0.46 & 0.41 & 0.44 & 0.43 & 0.03 & 0.32 & 0.55 & 0.92 & 0.54 \\
\hline Ruminobacter & 0.87 & 1.31 & 1.28 & 1.62 & 0.19 & 0.10 & 0.90 & 0.16 & 0.02 \\
\hline Clostridiaceae $^{2}$ & 0.82 & 0.73 & 0.75 & 0.89 & 0.05 & 0.26 & 0.86 & 0.04 & 0.38 \\
\hline Lachnospiraceae Ruminococcus & 0.42 & 0.47 & 0.52 & 0.51 & 0.06 & 0.54 & 0.47 & 0.84 & 0.26 \\
\hline
\end{tabular}

${ }^{1}$ Control $=$ no yeast treatment; LLY and HLY $=$ low $\left(5.7 \times 10^{7} \mathrm{cfu} / \mathrm{cow}\right.$ per day $)$ and high $\left(6.0 \times 10^{8} \mathrm{cfu} /\right.$ cow per day $)$ doses of live Saccharomyces cerevisiae YE1496 (DuPont Pioneer, Johnston, IA); HDY = high dose $\left(6.0 \times 10^{8} \mathrm{cfu} / \mathrm{cow}\right.$ per day) of killed Saccharomyces cerevisiae YE1496.

${ }^{2}$ Uncultured or unidentified genus in the corresponding family.

terium $(P=0.12)$ but increased that of YS2 $(P=0.12)$. Adding live yeast to the diet instead of killed yeast increased or tended to increase the relative abundance of Ruminococcaceae $(P=0.08)$, Ruminococcus $(P=0.01)$, Paraprevotellaceae $(P=0.05)$, and Coprococcus $(P=$ $0.09)$, and decreased those of Succinivibrionaceae $(P=$ $0.13)$, Ruminobacter $(P=0.01)$, Veillonellaceae $(P=$ $0.05)$, Porphyromonadaceae $(P=0.04)$ and $\mathrm{S} 24-7$ ( $P$ $=0.10$ ). Adding HDY to the diet decreased or tended to decrease the relative abundance of Lachnospiraceae $(P=0.14)$, Paraprevotellaceae $(P=0.01)$, Coprococcus $(P=0.07)$, and Paludibacter $(P=0.14)$ and increased those of Fibrobacter $(P=0.13)$, Ruminobacter $(P=$ $0.01)$, Porphyromonadaceae $(P=0.12)$, and Bifidobacterium $(P=0.05)$.

\section{Treatment Effects on Select Microbes Analyzed by $q P C R$}

We detected no treatment effects on total bacteria copy numbers in the solid (Table 4) or liquid fractions (Table 5). In the ruminal solid fraction, the relative abundance of $R$. albus, $R$. flavefaciens, Strep. bovis, $M$. elsdenii, and $P$. ruminicola were unaffected by dietary supplement (Table 4). However, adding LLY to the diet tended $(P=0.14)$ to increase the relative abundance of $F$. succcinogenes. Increasing the dose of live yeast decreased $(P=0.02)$ the relative abundance of $B$. fibrosolvens. Adding live yeast instead of killed yeast increased $(P=0.04)$ the relative abundance of $F$. succinogenes and decreased $(P=0.05)$ that of $S$. ruminantium. Adding HDY to the diet tended $(P=0.15)$ to decrease the relative abundance of $B$. fibrosolvens and protozoa $(P=0.14$ and 0.05 , respectively).

In the liquid fraction, the relative abundance of $F$. succinogenes, R. flavefaciens, B. fibrisolvens, M. elsdenii, P. ruminicola, and protozoa were not affected by diet (Table 5). Adding LLY to the diet tended to decrease the relative abundance of $R$. albus $(P=0.12)$ and increase that of $S$. ruminantium $(P=0.14)$. Increasing the dose of live yeast or adding live yeast instead of killed yeast had no effect on the relative abundance of bacteria in the liquid fraction. Adding HDY to the diet tended to increase the relative abundance of $S$. ruminantium $(P=0.11)$ and Strep. bovis $(P=0.06)$.

The quantity of Saccharomyces cerevisiae strain YE1496 used in the qPCR analysis was below the detection limit $\left(5 \times 10^{3}\right.$ cells/g of sample $)$ in all the samples.

\section{Comparison of Relative Abundance of Specific Bacteria Analyzed by Sequencing and QPCR}

We compared the abundance of OTU assigned taxonomically as the defined species of interest (see below) with qPCR results. The relationship between MiSeq 
and $\mathrm{qPCR}$ estimates of the relative abundance of $F$. succinogenes $\left(\mathrm{R}^{2}=0.60, P<0.001\right)$ in the ruminal solid fraction was more precise than those of $R$. flavefaciens $\left(\mathrm{R}^{2}=0.22, P<0.001\right)$, S. ruminantium $\left(\mathrm{R}^{2}\right.$ $=0.05, P<0.001)$, and $M$. elsdenii $\left(\mathrm{R}^{2}=0.14, P\right.$ $<0.001$; Figure 6$)$. In the ruminal liquid fraction, the relationships between MiSeq and $\mathrm{qPCR}$ estimates of the relative abundance of $F$. succinogenes $\left(\mathrm{R}^{2}=0.16\right.$, $P<0.01)$, R. flavefaciens $\left(\mathrm{R}^{2}=0.11, P<0.01\right)$, and M. elsdenii $\left(\mathrm{R}^{2}=0.11, P<0.01\right)$ were not as precise as those in the solid fraction, but that of $S$. ruminantium was similar $\left(\mathrm{R}^{2}=0.08, P<0.01 ;\right.$ Figure 7$)$. These data indicate that the relationship was more precise when the relative abundance of the species was higher.

\section{DISCUSSION}

\section{Relative Abundance of Taxa}

As in the present study, others have noted that Prevotella was the most abundant genus in ruminal samples (Stevenson and Weimer, 2007; Wu et al., 2012). Based on qPCR analysis, Stevenson and Weimer (2007) reported that Prevotella accounted for 42 to $60 \%$ of the bacterial rRNA gene copies in rumen samples. Also, the relative abundance of Fibrobacter in the ruminal solid fraction in the present study agrees with Lee et al. (2012), who reported that Fibrobacter was the second most dominant genus in particle-associated bacteria in ruminal fluid samples (4.3 to $10 \%$ of the total bacterial sequences). In addition, the high relative abundance of an unknown genus in the family Succinivibrionaceae in the ruminal liquid versus solid fraction agrees with the findings of Castro-Carrera et al. (2014).

In the present study, only a small proportion of sequences could be assigned to the species level due to the limited number of cultured species and the limited power of $16 \mathrm{~S}-\mathrm{V} 4$ region for species identification. Consequently, sequences were not assigned beyond the genus level for the examination of treatment effects. The level of sequence assignment to the genus level $(65.8 \%)$ in the present study was greater than that $(53 \%)$ reported by Pinloche et al. (2013) with 454 pyrosequencing, which might be because a different region of the $16 \mathrm{~S}$ rRNA gene was amplified, and different database and methods were used to assign taxa. Henderson et al. (2013) cautioned that it is almost impossible to be sure that current DNA isolation methods truly represent the entire ruminal microbial community. Also, the apparent microbial communities detected in this study may not be directly comparable with those from other studies that used a different DNA isolation method.

Table 3. Effect of supplementing 2 levels of live yeast or 1 level of killed yeast on the bacterial composition (relative \%) of the ruminal liquid fraction of dairy cows as analyzed by MiSeq (Illumina Inc., San Diego, CA) sequencing (experiment 1)

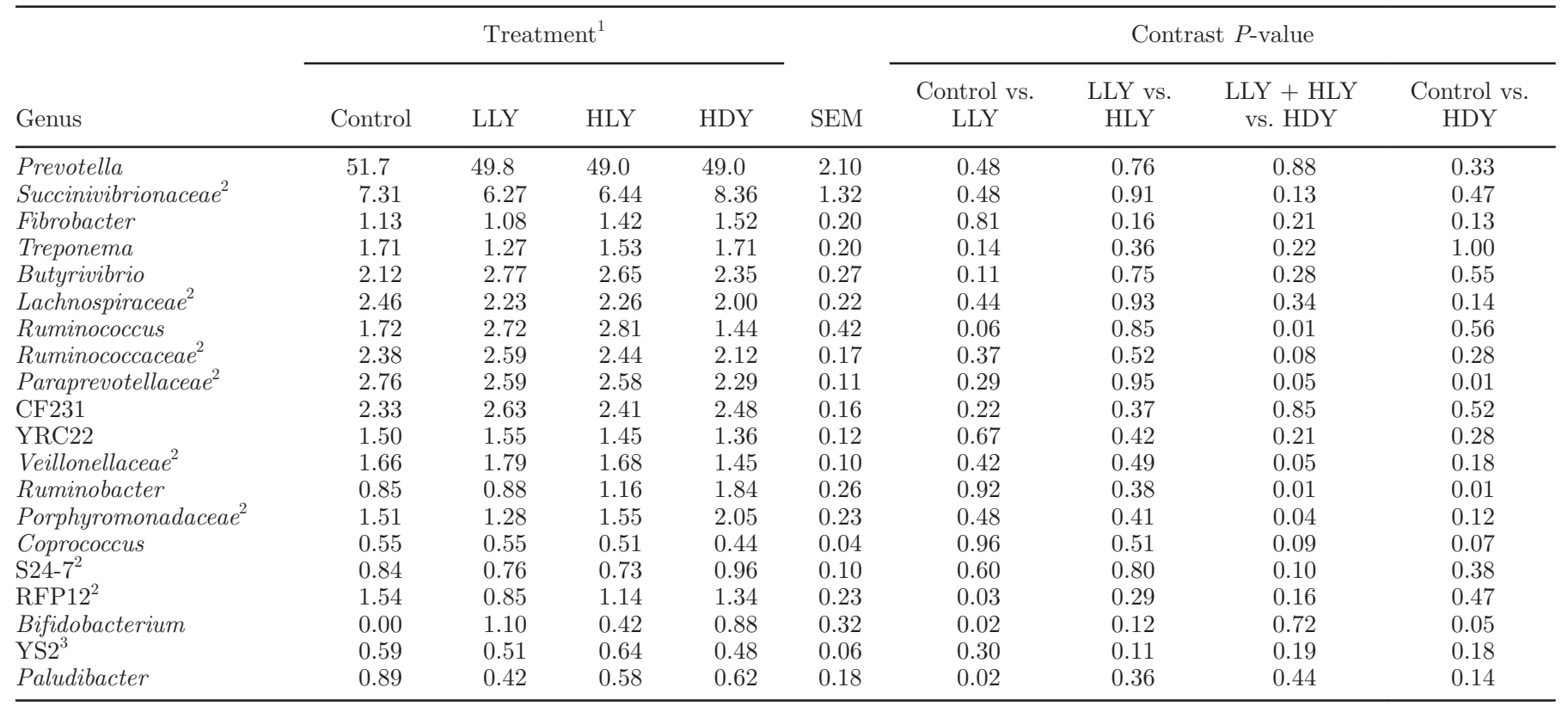

${ }^{1}$ Control $=$ no yeast treatment; LLY and HLY $=$ low $\left(5.7 \times 10^{7} \mathrm{cfu} /\right.$ cow per day $)$ and high $\left(6.0 \times 10^{8} \mathrm{cfu} /\right.$ cow per day $)$ doses of live Saccharomyces cerevisiae YE1496 (DuPont Pioneer, Johnston, IA); HDY $=$ high dose $\left(6.0 \times 10^{8}\right.$ cfu/cow per day) of killed Saccharomyces cerevisiae YE1496.

${ }^{2}$ Uncultured or unidentified genus in the corresponding family.

${ }^{3}$ Uncultured or unidentified genus in order YS2. 

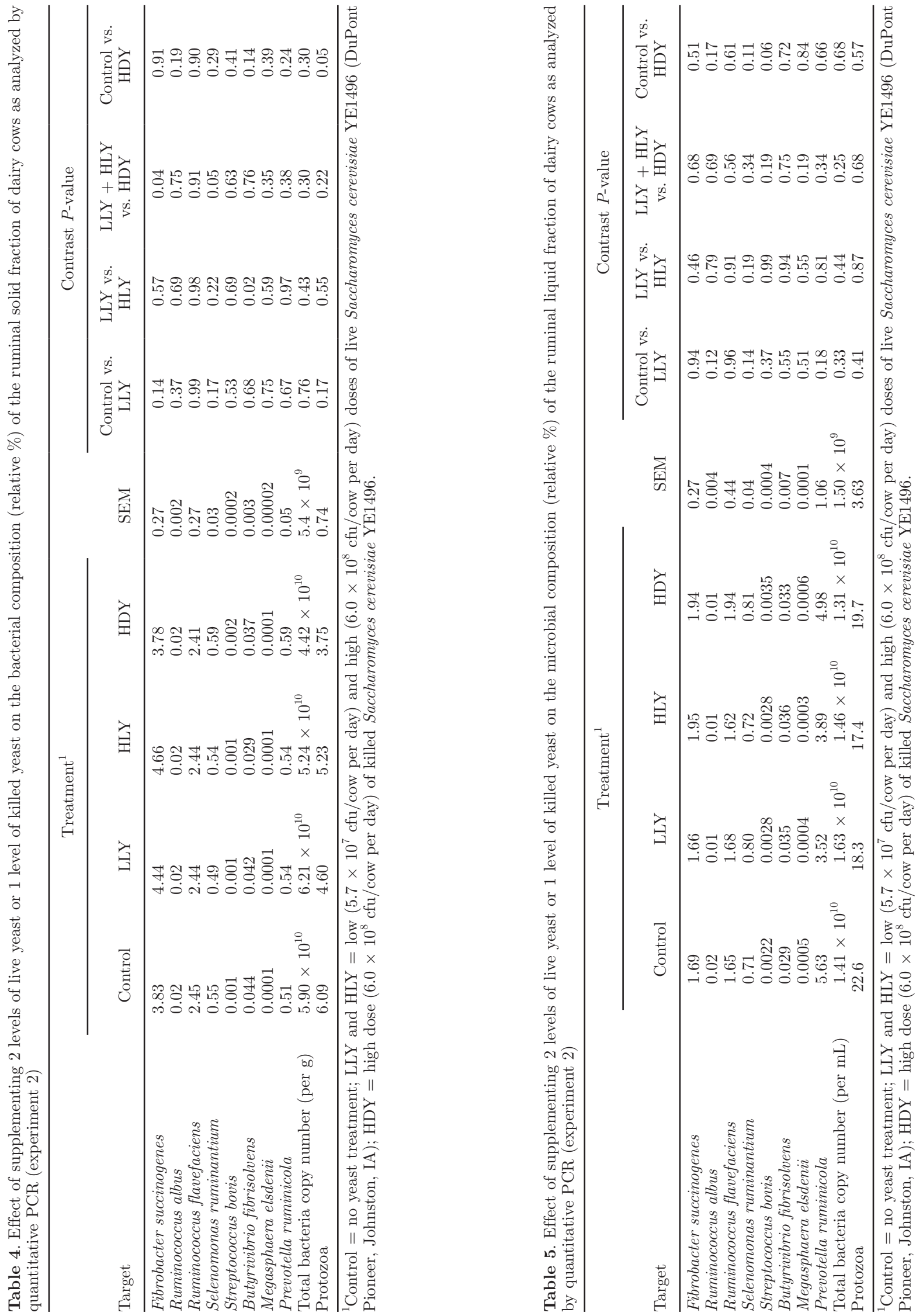
JIANG ET AL.

(a) F. succinogenes in the rumen

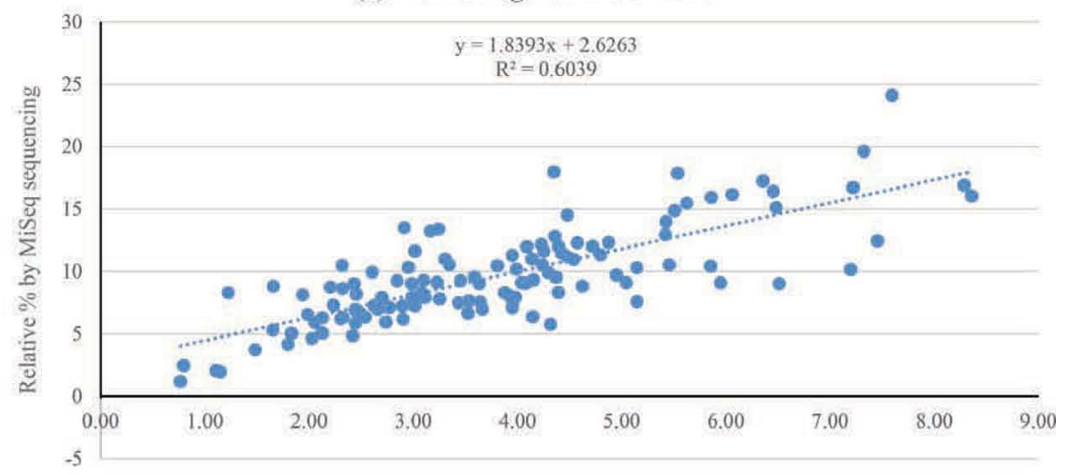

(b) R. flavefaciens in the rumen

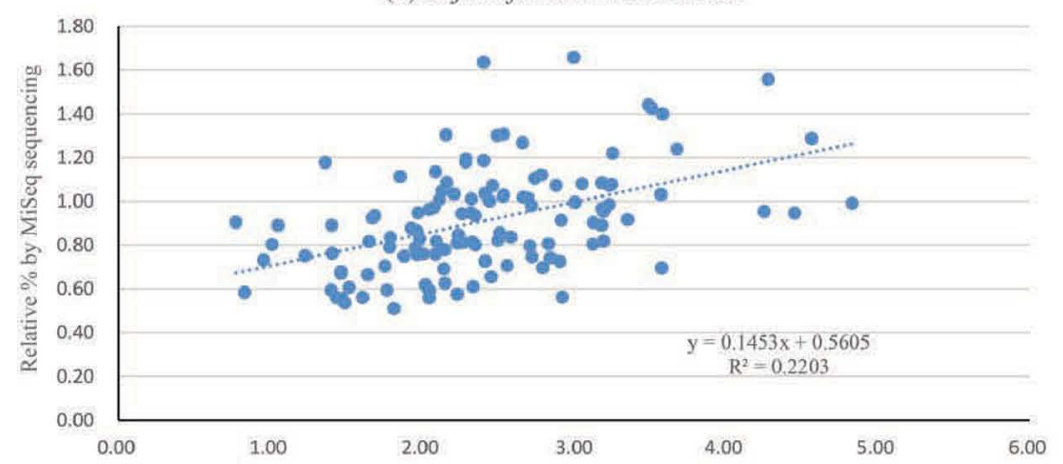

(c) S. ruminantium in the rumen

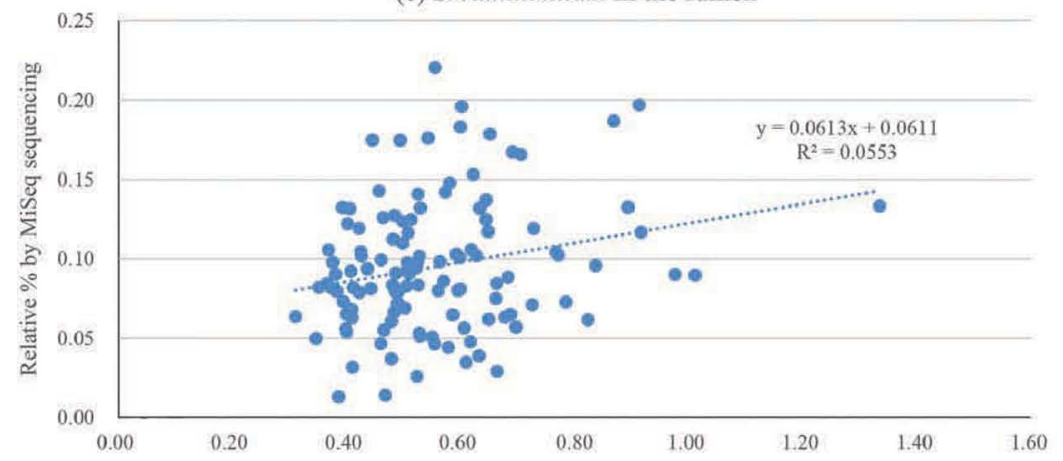

(d) M. elsdenii in the rumen

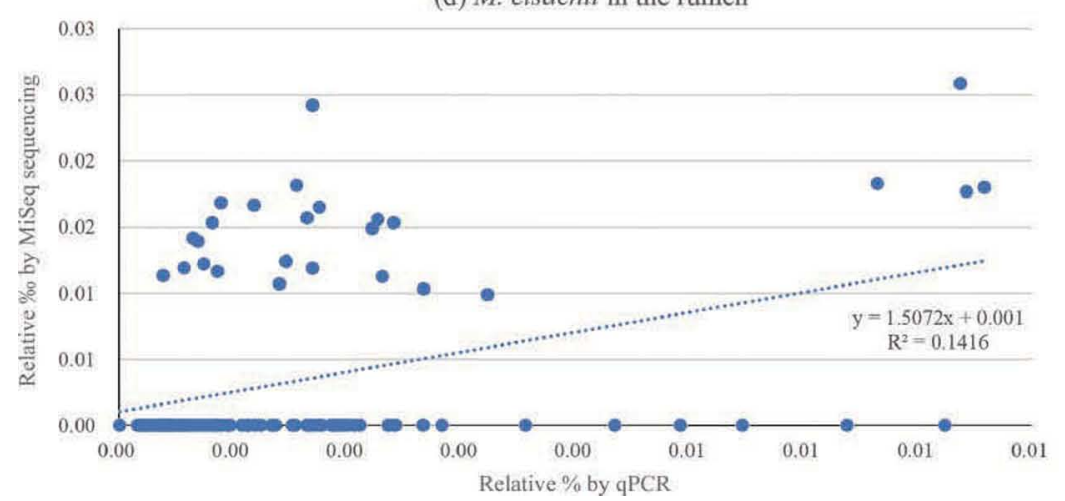

Figure 6. Relationship between estimates of the relative abundance of (a) Fibrobacter succinogenes, (b) Ruminococcus flavefaciens, (c) Selenomonas ruminantium, and (d) Megasphaera elsdenii in the ruminal solid fraction quantified by MiSeq (Illumina Inc., San Diego, CA) sequencing (experiment 1) and quantitative PCR (experiment 2). Color version available online. 
(a) F. succinogenes in the rumen

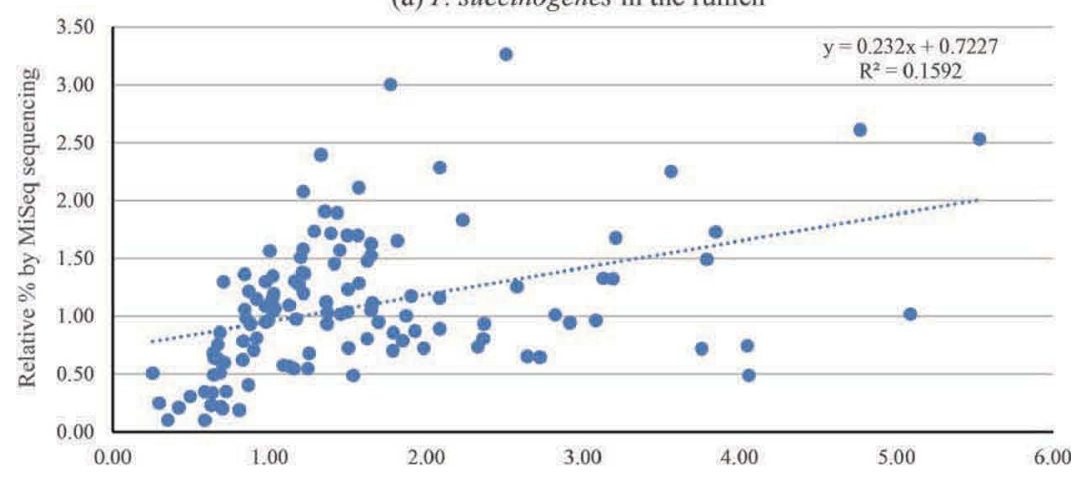

(b) R. flavefaciens in the rumen

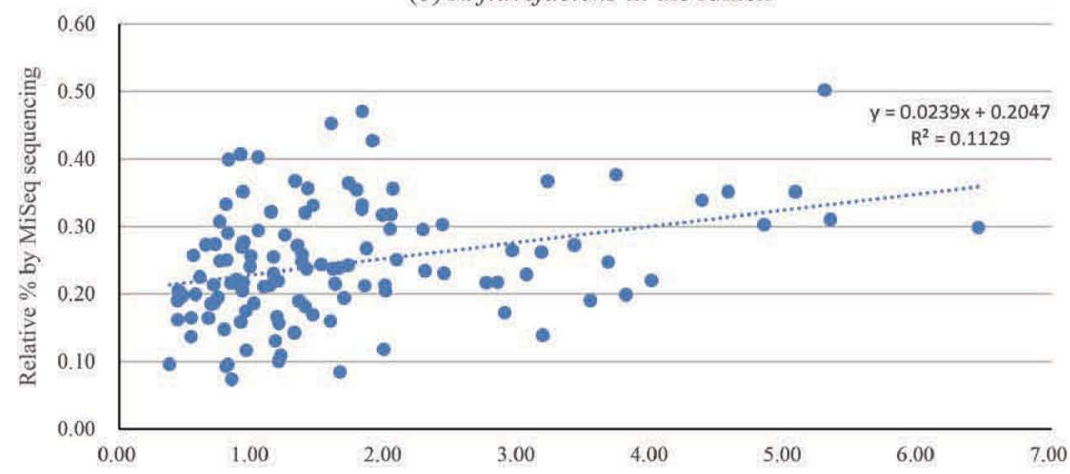

(c) S. ruminantium in the rumen

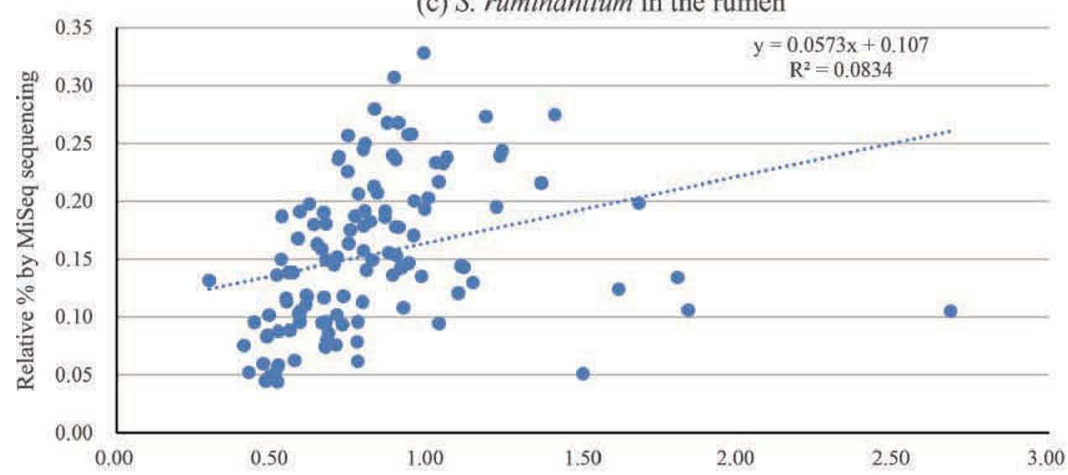

(d) M. elsdenii in the rumen

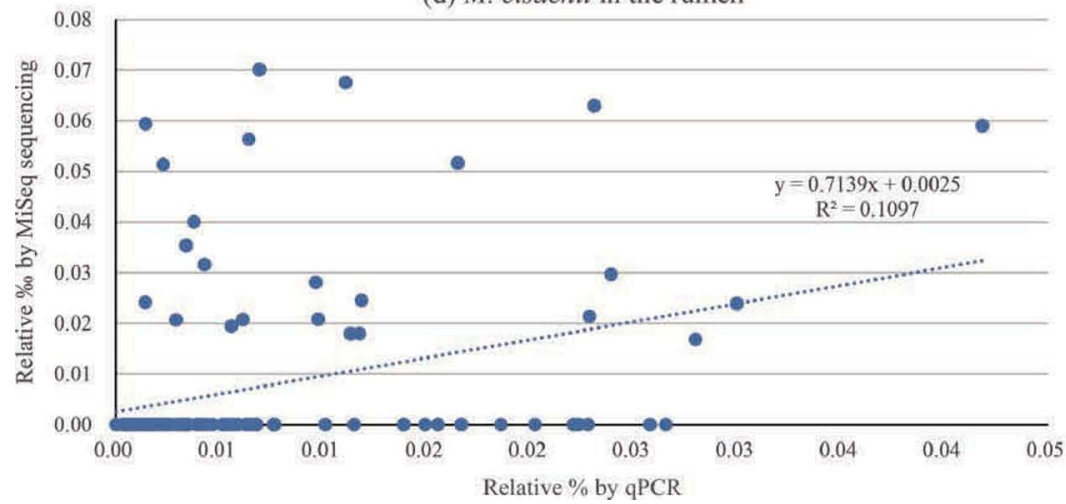

Figure 7. Relationship between estimates of the relative abundance of (a) Fibrobacter succinogenes, (b) Ruminococcus flavefaciens, (c) Selenomonas ruminantium, and (d) Megasphaera elsdenii in the ruminal liquid fraction quantified by MiSeq (Illumina Inc., San Diego, CA) sequencing (experiment 1) and quantitative PCR (experiment 2). Color version available online. 


\section{Treatment Effects on Dominant Bacteria Based on MiSeq Sequencing}

The ensuing descriptions use published information about substrate utilization by cultured ruminal bacteria genera or species to explain the treatment effects in this study. These explanations are not definitive because of the low number of ruminal bacteria that have been cultivated, the low number of sequences that were assigned to the species level in this study, and potential differences among strains and species in substrate utilization.

Adding LLY to the diet increased the relative abundance of some genera known for fermentation of cellulose (Ruminococcus, Russell, 2002; Suen et al., 2011, liquid fraction), starch, and sugars (Bifidobacterium, solid and liquid fractions) and decreased that of Treponema (solid and liquid fractions), a genus known for pectin utilization (Stewart et al., 1997; Russell, 2002; Vos et al., 2011). The increase in the relative abundance of Ruminococcus partly explains how adding LLY to the diet increased the in vivo digestibility of DM and NDF and the performance of the cows in the corresponding animal trial (Jiang et al., 2016). However, the relative abundance of Ruminococcus was increased only in the liquid fraction by LLY. Yet particle-associated Ruminococcus plays a more important role in NDF digestion than Ruminococcus in the liquid fraction, because the former is attached to feed particles and is more abundant, because the solid fraction contains $92 \%$ of total bacteria (Mullins et al., 2013). In addition, genus Ruminococcus also includes amylolytic bacteria such as Ruminococcus bromii (Larue et al., 2005), which is often present in the rumen of grain-fed cattle (Tajima et al., 2000). Therefore, LLY-induced increases in DM and NDF digestibility and milk production by cows in the performance study may be due to factors other than the increase in abundance of Ruminococcus in the liquid fraction.

Adding LLY to the diet also increased the relative abundance in the liquid fraction of Butyrivibrio, which uses a variety of substrates, such as cellulose, starch, sugar, and protein (Weimer, 1996; Russell, 2002). In the solid fraction, adding LLY to the diet decreased the relative abundance of Coprococcus and an unknown genus that belongs to the family Lachnospiraceae. The implications of these changes are unclear because $B u$ tyrivibrio can use a large variety of substrates and there is limited knowledge available about the function of Coprococcus and the unidentified genus in family Lachnospiraceae.

Increasing the dose of live yeast increased the relative abundance of Treponema in the solid fraction, decreased that of CF231 and an unknown genus in family
Paraprevotellaceae, increased the relative abundance of YS2 in the liquid fraction, and decreased that of Bifidobacterium in the solid and liquid fractions. The increase in the relative abundance of Treponema by increasing the live yeast dose contradicts the decrease in relative abundance of Treponema in both the liquid and solid fractions by dietary addition of LLY. This suggests that a lower yeast dose was associated with decreased Treponema relative abundance and greater milk production (Jiang et al., 2016). However, because Treponema is known for pectin fermentation in the rumen (Stewart et al., 1997), other ruminal bacteria likely played a greater role in the milk response.

The stimulation of Ruminococcus, a cellulolytic bacterium, by live yeast but not by killed yeast is consistent with the increases in NDF and ADF digestibility by these treatments in the animal experiment (Jiang et al., 2016). Some of the major ruminal bacteria in the genus Ruminobacter, such as Ruminobacter amylophilus, ferment starch (Cotta, 1988; Anderson, 1995); hence, adding live yeast instead of killed yeast to the diet may have decreased the relative abundance of starch fermenters. In addition, live yeast but not killed yeast changed the abundance of S24-7, and genera within Clostridiaceae, Succinivibrionaceae, and Porphyromonadaceae. However, the implication of these changes is unclear because of the unknown functions of these bacteria.

Adding killed yeast to the diet increased the relative abundance of starch and sugar digesters, Ruminobacter and Bifidobacterium, in ruminal liquid and solid fractions, and increased that of some fibrolytic bacteria (e.g., Fibrobacter) in the liquid fraction. Live yeast may have been more effective than killed yeast at increasing NDF and DM digestibility in the animal study (Jiang et al., 2016), because they stimulated Ruminococcus in the solid and liquid fractions, whereas HDY stimulated only Fibrobacter in the liquid fraction, where it was less prevalent than Ruminococcus (Figure 2). Adding killed yeast also altered the relative abundance of unknown genera in Lachnospiraceae and Porphyromonadaeae. However, due to limited knowledge about these families, the implication of these changes is unknown.

\section{Bacteria Candidates for Future Study}

In the present study, the most dominant bacteria that responded to addition of LLY to the diet, and whose functions are among the least understood in relation to the mode of action of yeast, include an unidentified genus in the family Paraprevotellaceae in the liquid fraction, and CF231, Treponema, and an unidentified genus in the family Lachnospiraceae in the solid fraction. The relative abundance of the unidentified genus 
in the family Paraprevotellaceae was increased by $12 \%$ in the liquid fraction, and that of CF231, an unclassified taxon, was increased by $30 \%$ in the solid fraction. Adding LLY decreased the relative abundance in the solid fraction of Treponema by $32 \%$ and decreased that of an unknown genus in the family Lachnospiraceae by $14 \%$. Due to the relative abundance of these bacteria in the liquid or solid ruminal fractions and the magnitude of their respective responses to LLY addition, which also increased diet digestibility and milk production by dairy cows (Jiang et al., 2016), future studies should aim to speciate, culture, and examine the function of these bacteria to better understand their roles in the mode of action of yeast.

\section{Treatment Effects on Select Microbes as Analyzed by qPCR}

The qPCR results suggest that adding LLY to the diet or adding live yeast instead of killed yeast may have increased DM and NDF digestibility in the animal trial (Jiang et al., 2016) by stimulating F. succinogenes in the solid fraction. Although LLY supplementation also decreased the relative abundance of $R$. albus in the liquid fraction, this may have not reduced the digestibility of NDF or DM (Jiang et al., 2016) because of the low relative abundance of $R$. albus in the liquid fraction ( $\leq 0.02 \%$ vs. $3.8-4.7 \%$ for $F$. succinogenes). The qPCR and sequencing results on the main fiber digesters differed. The sequencing results suggested that the relative abundance of Ruminococcus (but not Fibrobacter) was greater when LLY was added to the diet, whereas the $\mathrm{qPCR}$ results suggested the opposite. These differences are discussed further in the section below on differences between the results of both assays.

Increasing the live yeast dose decreased the relative abundance in the solid fraction of B. fibrisolvens, which uses a variety of substrates such as cellulose, hemicellulose, starch, sugar, and protein (Weimer, 1996; Russell, 2002). This may be one of the reasons why HLY did not increase milk yield and LLY did in the companion study.

The effect of the decreased protozoa abundance in the solid fraction by HDY is unclear, because protozoa use many different substrates and bacteria. The stimulation of amylolytic Strep. bovis (Asanuma and Hino, 2002) and S. ruminantium (Stewart et al., 1997; Russell, 2002) in the liquid fraction by dietary addition of HDY partly supports the sequencing data, which showed that different genera that contain amylolytic bacteria $(R u$ minobacter and Bifidobacterium) were stimulated by this treatment. The increase in the relative abundance of Strep. bovis by HDY supplementation as determined by qPCR agrees with the trend $(P=0.12)$ for ruminal lactate concentration to be increased by HDY in the animal experiment (Jiang et al., 2016).

The fate of the supplemented Saccharomyces cerevisiae YE1496 in the rumen remains unknown due to the fact that the quantities found in the rumen were below the detection limit for qPCR in this study. More studies are needed to explore the survival of supplemental live yeast in the rumen.

\section{Comparison of MiSeq and qPCR Estimates of the Relative Abundance of Bacteria}

Quantitative PCR is used to measure the copy numbers of a gene of interest, such as the 16S rRNA gene. We attempted to validate the MiSeq sequencing results with qPCR using selected species-specific primers commonly used in rumen microbial ecology research. The relationship between estimates of the relative abundance of $F$. succinogenes from $\mathrm{qPCR}$ and MiSeq sequencing was moderately precise, but those for $M$. elsdenii, $R$. flavefaciens, and S. ruminantium were weak. There are several potential reasons for the weak relationship.

First, differences in treatment effects on specific taxa from the $\mathrm{qPCR}$ and sequencing methods were partly due to differences between the techniques, such as the choice and specificity of the primers, particularly those used for qPCR, which are relatively older. Although both methods involve a PCR step, the MiSeq and qPCR primers target different regions. On the $16 \mathrm{~S}$ rRNA genes, highly conserved and hypervariable sequences are organized alternatively (Chakravorty et al., 2007). For MiSeq sequencing, the hypervariable region 4 (V4) of $16 \mathrm{~S}$ was amplified by primers that anneal to the flanking of conserved regions. For qPCR, to differentiate species, most species-specific primers were designed based on the regions containing adequate variation. In addition, degenerate primers were used to generate the V4 amplicons (Caporaso et al., 2010) to account for the sequence variability of different bacteria group. These could cause differences in the annealing kinetics of the primers and affect the efficiency of the PCR. In addition, the qPCR primers used also displayed identity to a few strains of closely related species and to some taxonomically unidentified sequences (Stevenson and Weimer 2007), which may yield higher abundance for these taxa.

Second, the V4 amplicon sequence analysis relies on a classification algorithm and a reference database to assign taxonomies to OTU. We used the Greengenes database because, to our knowledge, it is the only publicly available database that provides species-level resolution for some species. However, different classifiers can cause differences in recapturing the taxonomy 
information of $16 \mathrm{~S}$ rRNA sequences, even when the same reference database is used (Liu et al., 2008). In addition, for some species, the short 16S-V4 region may not provide the same classification as the full-length region or other segments of $16 \mathrm{~S}$ (Jeong et al., 2011). Furthermore, some bacteria are known to have different copies of $16 \mathrm{~S}$ operons with different sequences. Consequently, sequence-based analyses may classify the different copies as different species (Case et al., 2007).

These factors may contribute the lack of a correlation between the MiSeq and qPCR results. More systematic studies will be needed to identify a standard operating procedure for rumen microbial ecology studies.

Because $F$. succinogenes was more abundant than the other bacteria, the data suggest that the accuracy of the relationship between MiSeq and qPCR estimates of bacterial relative abundance increases with the abundance of the bacteria. Jami and Mizrahi (2012) reported that bacteria with low abundance when measured by qPCR were not detected using pyrosequencing; otherwise, similar abundance estimates were obtained with both methods. Differences in treatment effects on specific taxa from the qPCR and sequencing methods are partly due to differences between the techniques, particularly the choice of the primer. In addition, qPCR is quantitative, but sequencing is semiquantitative because of potential errors of reproducible homopolymer length (Kunin et al., 2010) and bias during sequencing (Firkins and $\mathrm{Yu}, 2015$ ). Isolation of DNA during qPCR also introduces bias in composition measurements. Nevertheless, both methods indicated that the relative abundance of different cellulolytic organisms was increased by adding LLY or by adding live yeast instead of killed yeast. Both methods also showed that adding killed yeast to the diet increased the relative abundance of different amylolytic organisms. Pinloche et al. (2013) used 454 pyrosequencing and serial analysis of V1 ribosomal sequence tags to examine the effects of adding live yeast to dairy cow diets on ruminal bacterial diversity. As in this present study, they concluded that each method showed that adding live yeast increased the relative abundance of a different fibrolytic bacterium. Both of the methods compared in this study revealed that yeast supplementation caused similar shifts in the population of bacteria that ferment specific nutrients, consistent with the findings of Pinloche et al. (2013).

The results of the present study partly support our first hypothesis that feeding live yeast alone or live yeast instead of killed yeast would increase the relative abundance of cellulolytic bacteria in the rumen. In addition, the results partly support our second hypothesis that similar bacterial diversity responses to yeast treatments will be found with qPCR and MiSeq sequencing.

\section{CONCLUSIONS}

The MiSeq sequencing and qPCR methods revealed different treatment effects on the relative abundance of specific ruminal bacteria taxa. Nevertheless, both methods revealed that yeast supplementation caused some similar shifts in the relative abundance of bacteria that ferment specific nutrients. The MiSeq sequencing and $\mathrm{qPCR}$ methods revealed that adding LLY to the diet or adding live yeast instead of killed yeast increased the relative abundance of different ruminal cellulolytic bacteria (Ruminococcus and F. succinogenes, respectively). The respective methods also showed that adding HDY to the diet increased the relative abundance of different amylolytic bacteria (Ruminobacter and Bifidobacteria vs. Strep. bovis and S. ruminantium, respectively). The relationship between estimates of the relative abundance of $F$. succinogenes from qPCR and MiSeq sequencing methods was moderately precise, but those for $M$. elsdenii, $R$. flavefaciens, and $S$. ruminantium were weak. The present study confirmed the low relative abundance of several culturable, wellknown ruminal bacteria and indicated that the relative abundance and diversity of bacteria in the ruminal solid and liquid fractions differed. The most dominant ( $\geq 1 \%$ of total sequences) bacteria that responded to LLY addition whose functions are among the least understood in relation to the mode of action of yeast included Paraprevotellaceae, CF231, Treponema, and Lachnospiraceae. Future studies should aim to speciate, culture, and examine the function of these bacteria to better understand their roles in the mode of action of yeast. More systematic studies are needed to develop a standard operation procedure for rumen microbial ecology study.

\section{ACKNOWLEDGMENTS}

We gratefully acknowledge funding of this study by DuPont Pioneer. We are also grateful to the staff of the University of Florida Dairy Unit for their assistance with the animal experiment.

\section{REFERENCES}

Anderson, K. L. 1995. Biochemical analysis of starch degradation by Ruminobacter amylophilus 70. Appl. Environ. Microbiol. 61:14881491.

Asanuma, N., and T. Hino. 2002. Regulation of fermentation in a ruminal bacterium, Streptococcus bovis, with special reference to rumen acidosis. Anim. Sci. J. 73:313-325.

Bach, A., I. Iglesias, and M. Devant. 2007. Daily rumen pH pattern of loose-housed dairy cattle as affected by feeding pattern and live yeast supplementation. Anim. Feed Sci. Technol. 136:146-153.

Beauchemin, K. A., M. Kreuzer, F. O'Mara, and T. A. McAllister. 2008. Nutritional management for enteric methane abatement: A review. Aust. J. Exp. Agric. 48:21-27. 
Bokulich, N. A., S. Subramanian, J. J. Faith, D. Gevers, J. I. Gordon, R. Knight, D. A. Mills, and J. G. Caporaso. 2013. Quality-filtering vastly improves diversity estimates from Illumina amplicon sequencing. Nat. Methods 10:57-59.

Callaway, E. S., and S. A. Martin. 1997. Effects of a Saccharomyces cerevisiae culture on ruminal bacteria that utilize lactate and digest cellulose. J. Dairy Sci. 80:2035-2044.

Caporaso, J. G., J. Kuczynski, J. Stombaugh, K. Bittinger, F. D. Bushman, E. K. Costello, N. Fierer, A. Gonzalez Pena, J. K. Goodrich, J. I. Gordon, G. A. Huttley, S. T. Kelley, D. Knights, J. E. Koenig, R. E. Ley, C. A. Lozupone, D. McDonald, B. D. Muegge, M. Pirrung, J. Reeder, J. R. Sevinsky, P. J. Turnbaugh, W. A. Walters, J. Widmann, T. Yatsunenko, J. Zaneveld, and R. Knight. 2010. QIIME allows analysis of high-throughput community sequencing data. Nat. Methods 7:335-336.

Case, R. J., Y. Boucher, I. Dahllöf, C. Holmström, W. F. Doolittle, and S. Kjelleberg. 2007. Use of $16 \mathrm{~S}$ rRNA and rpoB genes as molecular markers for microbial ecology studies. Appl. Environ. Microbiol. 73:278-288.

Castro-Carrera, T., P. G. Toral, P. Frutos, N. R. McEwan, G. Hervás, L. Abecia, E. Pinloche, S. E. Girdwood, and A. Belenguer. 2014. Rumen bacterial community evaluated by 454 pyrosequencing and terminal restriction fragment length polymorphism analyses in dairy sheep fed marine algae. J. Dairy Sci. 97:1661-1669.

Chakravorty, S., D. Helb, M. Burday, N. Connell, and D. Alland. 2007. A detailed analysis of $16 \mathrm{~S}$ ribosomal RNA gene segments for the diagnosis of pathogenic bacteria. J. Microbiol. Methods 69:330-339.

Chaucheyras, F., G. Fonty, G. Bertin, J. M. Salmon, and P. Gouet. 1996. Effects of a strain of Saccharomyces cerevisiae (Levucell SC), a microbial additive for ruminants, on lactate metabolism in vitro. Can. J. Microbiol. 42:927-933.

Chaucheyras-Durand, F., and G. Fonty. 2001. Establishment of cellulolytic bacteria and development of fermentative activities in the rumen of gnotobiotically-reared lambs receiving the microbial additive Saccharomyces cerevisiae CNCM I-1077. Reprod. Nutr. Dev. 41:57-68.

Chaucheyras-Durand, F., and G. Fonty. 2002. Influence of a probiotic yeast (Saccharomyces cerevisiae CNCM I-1077) on microbial colonization and fermentation in the rumen of newborn lambs. Microb. Ecol. Health Dis. 14:30-36.

Cotta, M. A. 1988. Amylolytic activity of selected species of ruminal bacteria. Appl. Environ. Microbiol. 54:772-776.

DeSantis, T. Z., P. Hugenholtz, N. Larsen, M. Rojas, E. L. Brodie, K. Keller, T. Huber, D. Dalevi, P. Hu, and G. L. Andersen. 2006. Greengenes, a chimera-checked $16 \mathrm{~S}$ rRNA gene database and workbench compatible with ARB. Appl. Environ. Microbiol. 72:5069-5072.

Edgar, R. C. 2010. Search and clustering orders of magnitude faster than BLAST. Bioinformatics 26:2460-2461.

Erasmus, L. J., P. H. Robinson, A. Ahmadi, R. Hinders, and J. E. Garrett. 2005. Influence of prepartum and postpartum supplementation of a yeast culture and monensin, or both, on ruminal fermentation and performance of multiparous dairy cows. Anim. Feed Sci. Technol. 122:219-239.

Ferraretto, L. F., R. D. Shaver, and S. J. Bertics. 2012. Effect of dietary supplementation with live-cell yeast at two dosages on lactation performance, ruminal fermentation, and total-tract nutrient digestibility in dairy cows. J. Dairy Sci. 95:4017-4028.

Firkins, J. L., and Z. Yu. 2015. Ruminant nutrition symposium: How to use data on the rumen microbiome to improve our understanding of ruminant nutrition. J. Anim. Sci. 93:1450-1470.

Frey, K. G., E. Herrera-Galeano, C. L. Redden, T. V. Luu, S. L. Servetas, A. J. Mateczun, V. P. Mokashi, and K. A. Bishop-Lilly. 2014. Comparison of three next-generation sequencing platforms for metagenomic sequencing and identification of pathogens in blood. BMC Genomics 15:96-110.

Henderson, G., F. Cox, S. Kittelmann, V. H. Miri, M. Zethof, S. J. Noel, G. C. Waghorn, and P. H. Janssen. 2013. Effect of DNA extraction methods and sampling techniques on the apparent struc- ture of cow and sheep rumen microbial communities. PLoS One 8:e74787.

Jami, E., and I. Mizrahi. 2012. Composition and similarity of bovine rumen microbiota across individual animals. PLoS One 7:e33306.

Jeong, E., J. W. Hong, J. A. Min, D. W. Lee, M. Y. Sohn, W. J. Lee, J. Y. Lee, and Y. M. Park. 2011. Topical ALA-photodynamic therapy for acne can induce apoptosis of sebocytes and down-regulate their TLR-2 and TLR-4 expression. Ann. Dermatol. 23:23-32.

Jiang, Y., I. M. Ogunade, K. G. Arriola, C. Staples, and A. T. Adesogan. 2016. Effects of the dose and viability of Saccharomyces cerevisiae. II Ruminal fermentation and performance of lactating dairy cattle. J. Dairy Sci. Submitted.

Kocherginskaya, S. A., R. I. Aminov, and B. A. White. 2001. Analysis of the rumen bacterial diversity under two different diet conditions using denaturing gradient gel electrophoresis, random sequencing and statistical ecology approaches. Anaerobe 7:119-134.

Krause, M. K., and G. R. Oetzel. 2006. Understanding and preventing subacute ruminal acidosis in dairy herds: A review. Anim. Feed Sci. Technol. 126:215-236.

Kunin, V., A. Engelbrektson, H. Ochman, and P. Hugenholtz. 2010. Wrinkles in the rare biosphere: Pyrosequencing errors can lead to artificial inflation of diversity estimates. Environ. Microbiol. 12:118-123.

Larue, R., Z. Yu, V. A. Parisi, A. R. Egan, and M. Morrison. 2005. Novel microbial diversity adherent to plant biomass in the herbivore gastrointestinal tract, as revealed by ribosomal intergenic spacer analysis and rrs gene sequencing. Environ. Microbiol. 7:530-543.

Lee, H. J., J. Y. Jung, Y. K. Oh, S. S. Lee, E. L. Madsen, and C. O. Jeon. 2012. Comparative survey of rumen microbial communities and metabolites across one caprine and three bovine groups, using bar-coded pyrosequencing and $1 \mathrm{H}$ nuclear magnetic resonance spectroscopy. Appl. Environ. Microbiol. 78:5983-5993.

Lila, Z. A., N. Mohammed, T. Yasui, Y. Kurokawa, S. Kanda, and H. Itabashi. 2004. Effects of a twin strain of Saccharomyces cerevisiae live cells on mixed ruminal microorganism fermentation in vitro. J. Anim. Sci. 82:1847-1854.

Liu, Z., T. Z. DeSantis, G. L. Andersen, and R. Knight. 2008. Accurate taxonomy assignments from $16 \mathrm{~S}$ rRNA sequences produced by highly parallel pyrosequencers. Nucleic Acids Res. 36:e120.

Loman, N. J., R. V. Misra, T. J. Dallman, C. Constantinidou, S. E. Gharbia, J. Wain, and M. J. Pallen. 2012. Performance comparison of benchtop high-throughput sequencing platforms. Nat. Biotechnol. 30:434-439.

Lozupone, C., and R. Knight. 2005. UniFrac: A new phylogenetic method for comparing microbial communities. Appl. Environ. Microbiol. 71:8228-8235.

Maeda, H., C. Fujimoto, Y. Haruki, T. Maeda, S. Kokeguchi, M. Petelin, H. Arai, I. Tanimoto, F. Nishimura, and S. Takashiba. 2003. Quantitative real time PCR using TaqMan and SYBR Green for Actinobacillus actinomycetemcomitans, Porphyromonas gingivalis, Prevotella intermedia, tetQ gene and total bacteria. FEMS Immunol. Med. Microbiol. 39:81-86.

Magoč, T., and S. Salzberg. 2011. FLASH: Fast length adjustment of short reads to improve genome assemblies. Bioinformatics $27: 2957-2963$.

Michalet-Doreau, B., I. Fernandez, C. Peyron, L. Millet, and G. Fonty. 2001. Fibrolytic activities and cellulolytic bacterial community structure in the solid and liquid phases of rumen contents. Reprod. Nutr. Dev. 41:187-194.

Mullins, C. R., L. K. Mamedova, A. J. Carpenter, Y. Ying, M. S. Allen, I. Yoon, and B. J. Bradford. 2013. Analysis of rumen microbial populations in lactating dairy cattle fed diets varying in carbohydrate profiles and Saccharomyces cerevisiae fermentation product. J. Dairy Sci. 96:5872-5881.

National Research Council. 2001. Nutrient Requirements of Dairy Cattle. 7th rev. ed. Natl. Acad. Sci., Washington, DC.

Pinloche, E., N. McEwan, J.-P. Marden, C. Bayourthe, E. Auclair, and C. J. Newbold. 2013. The effects of a probiotic yeast on the bacterial diversity and population structure in the rumen of cattle. PLoS One 8:e67824. 
Rossi, F., A. D. Luccia, D. Vincenti, and P. S. Cocconcelli. 2004. Effects of peptidic fractions from Saccharomyces cerevisiae culture on growth and metabolism of the ruminal bacteria Megasphaera elsdenii. Anim. Res. 53:177-186.

Russell, J. 2002. Rumen microbiology and its role in ruminant nutrition. James B. Russell, Ithaca, NY.

Sandri, M., C. Manfrina, A. Pallavicinia, and B. Stefanona. 2014. Microbial biodiversity of the liquid fraction of rumen content from lactating cows. Animal 8:572-579.

SAS. 2016. Guidelines for selecting the covariance structure in mixed model analysis. Accessed Jun. 15, 2016. http://www2.sas.com/ proceedings/sugi30/198-30.pdf.

Schloss, P. D., S. L. Wescott, T. Ryabin, J. R. Hall, M. Hartmann, E. B. Hollister, R. A. Lesniewski, B. B. Oakley, D. H. Parks, C. J. Robinson, J. W. Sahl, B. Stres, G. G. Thallinger, D. J. Van Horn, and C. F. Weber. 2009. Introducing mothur: Open-source, platform-independent, community-supported software for describing and comparing microbial communities. Appl. Environ. Microbiol. 75:7537-7541.

Stevenson, D. M., and P. J. Weimer. 2007. Dominance of Prevotella and low abundance of classical ruminal bacterial species in the bovine rumen revealed by relative quantification real-time PCR. Appl. Microbiol. Biotechnol. 75:165-174.

Stewart, C. S., H. J. Flint, and M. P. Bryant. 1997. The rumen bacteria. Pages 10-72 in The Rumen Microbial Ecosystem. P. N. Hobson and C. S. Stewart, ed. Blackie Academic and Professional Publishers, London, UK.

Suen, G., D. M. Stevenson, D. C. Bruce, O. Chertkov, A. Copeland, J. F. Cheng, C. Detter, J. C. Detter, L. A. Goodwin, C. S. Han, L. J. Hauser, N. N. Ivanova, N. C. Kyrpides, M. L. Land, A. Lapidus, S. Lucas, G. Ovchinnikova, S. Pitluck, R. Tapia, T. Woyke, J.
Boyum, D. Mead, and P. J. Weimer. 2011. Complete genome of the cellulolytic ruminal bacterium Ruminococcus albus 7. J. Bacteriol. 193:5574-5575.

Sylvester, J. T., S. K. R. Karnati, Z. Yu, M. Morrison, and J. L. Firkins. 2004. Development of an assay to quantify rumen ciliate protozoal biomass in cows using real-time PCR. J. Nutr. 134:33783384 .

Tajima, K., R. I. Aminov, T. Nagamine, K. Ogata, M. Nakamura, H. Matsui, and Y. Benno. 1999. Rumen bacterial diversity as determined by sequence analysis of $16 \mathrm{~S}$ rDNA libraries. FEMS Microbiol. Ecol. 29:159-169.

Tajima, K., S. Arai, K. Ogata, T. Nagamine, H. Matsui, M. Nakamura, R. I. Aminov, and Y. Benno. 2000. Rumen bacterial community transition during adaptation to high-grain diet. Anaerobe 6:273-284.

Vos, P., G. Garrity, D. Jones, N. R. Krieg, W. Ludwig, F. A. Rainey, K.-H. Schleifer, and W. B. Whitman. 2011. Bergey's Manual of Systematic Bacteriology: The Firmicutes. Vol. 3. Springer Science and Business Media, New York, NY.

Weimer, P. J. 1996. Why don't ruminal bacteria digest cellulose faster? J. Dairy Sci. 79:1496-1502.

Whitford, M. F., R. J. Foster, C. E. Beard, J. Gong, and R. M. Teather. 1998. Phylogenetic analysis of rumen bacteria by comparative sequence analysis of cloned 16S rRNA genes. Anaerobe 4:153-163.

Wu, S., R. L. Baldwin, W. Li, C. Li, E. E. Connor, and R. W. Li. 2012 The bacterial community composition of the bovine rumen detected using pyrosequencing of 16s rRNA genes. Metagenomics 1:1-11.

Zhang, H., P. Parameswaran, J. Badalamenti, B. E. Rittmann, and R. Krajmalnik-Brown. 2011. Integrating high-throughput sequencing and quantitative real-time PCR to analyze complex microbial communities. Methods Mol. Biol. 733:107-128. 